This manuscript has been accepted for publication in International Journal of Production Economics. https://doi.org/10.1016/j.ijpe.2019.07.035

\title{
The role of 3D printing and open design on adoption of socially sustainable supply chain innovation

\author{
*Ahmad Beltagui ${ }^{1}$, Nathan Kunz ${ }^{2}$, Stefan Gold ${ }^{3}$
}

\author{
*corresponding author \\ ${ }^{1}$ Operations and Information Management Dept., Aston Business School, Birmingham, \\ United Kingdom, a.beltagui@ aston.ac.uk \\ ${ }^{2}$ Coggin College of Business, University of North Florida, Jacksonville, USA \\ (nathan.kunz@unf.edu \\ ${ }^{3}$ Faculty of Economics and Management, University of Kassel, Germany (gold@uni- \\ kassel.de)
}

\begin{abstract}
Social sustainability is a growing concern for supply chain management, but questionable practices endure due to insufficient stakeholder pressure on the market leading firms. Meanwhile small, socially oriented firms may have the will but lack the means to change dominant practices when entering a market. In this context 3D printing may offer a solution, by leveraging the voluntary effort of individuals through open design and distributed production. A system dynamics approach is applied to the case of a socially oriented mobile phone producer, whose fair supply chain practices may initially appeal only to a niche market. We examine how open design of 3D printed mobile phone accessories helps overcome size-related resource constraints, facilitate market growth and ultimately generate sufficient consumer demand to alter the market leaders' supply chain practices, in favour of social sustainability. Our findings demonstrate the interaction between availability of 3D printers, consumer attitudes to social sustainability and the market entry. We discuss the implications for technology management, namely that 3D printing can help overcome resource constraints to support the diffusion of socially sustainable supply chain innovation.
\end{abstract}

Keywords: Additive Manufacturing, 3D Printing, Open Source Innovation, Social Sustainability, Open Design, System Dynamics. 


\subsection{Introduction}

The increasing adoption of three-dimensional printing (3DP) technologies in a variety of industries necessitates strategic decisions on how to use them (Mellor et al., 2014; Weller et al., 2015). This set of highly flexible, digital production techniques offers many opportunities in supply chain management (SCM) (Caviggioli and Ughetto, 2019). These include: minimising material wastage (Huang et al., 2013); reducing supply chain complexity through design consolidation (Khajavi et al., 2014; Rogers et al., 2016; Candi and Beltagui, 2019; Knofius et al., 2019); cost-effective low-volume production, e.g. for digital spare parts (Thiesse et al., 2015; Baumers et al., 2016; Chan et al., 2018; Chekurov et al., 2018) and reduced transport cost through localised production (Bogers et al., 2016; Schniederjans et al., 2017). These benefits suggest opportunities to improve (environmental) sustainability (Blowfield and Johnson, 2013; Despeisse et al., 2017). An opportunity that has received much less attention, however, is how 3DP may support social sustainability in supply chains. Although environmental sustainability has become an important concern for SCM theory and practice (Matthews et al., 2016), relatively less attention has been paid to social sustainability in physical goods supply chains (Zorzini et al., 2014). The Brundtland report defines sustainable development as "a development that meets the needs of the present without compromising the ability of future generations to meet their own needs" (WCED, 1987, p.8). This is operationalised through the triple bottom line (TBL) that places environmental and social dimensions on the same level as economic sustainability (Dyllick and Hockerts, 2002). Referring to this concept, Hassini et al. (2012, p.70) define sustainable SCM as "the management of supply chain operations, resources, information, and funds in order to maximize the supply chain profitability while at the same time minimizing the environmental impacts and maximizing the social well-being". For the purpose of this study, we focus on 
social sustainability within supply chains. According to the GRI G4 Sustainability Reporting Guidelines, social sustainability refers to human rights (e.g., forced labour), labour practices and decent work (e.g., occupational health and safety), product responsibility (e.g., customer privacy), or business-society interaction (e.g., local communities) (GRI, 2013). We consider a sustainable supply chain innovation to be the introduction of practices that make improvements to one or more of human rights, good labour practices, product stewardship, and good business-society relationship.

Due to the complexity, lack of transparency and physical distance of supply chains, consumers often lack awareness of the issues as well as motivation to enforce change (Gold et al., 2017). For example, wages and worker safety in some Chinese mobile phone factories improved only when media reports of suicides raised Western consumers' awareness of working conditions (Chan and Pun, 2010). In clothing supply chains, social responsibility is often overlooked until accidents such as the Rana Plaza factory collapse in Bangladesh raise consumers' awareness of working conditions (Huq et al., 2016). Public attention increased in the aftermath of the accident, which caused over a thousand deaths and led to prosecution of managers. Yet this awareness did not translate into effective corrective action by businesses or policy makers and saw minimal long-term impact on social sustainability in this supply chain (Chowdhury, 2017). Pagell and Shevchenko (2014) argue that large firms are unlikely to improve social sustainability without sufficient stakeholder pressure, meaning that until consumers stop buying their products, producers have no incentive to adopt sustainable SCM. In the absence of regulation or decisive consumer pressure, change in an industry's SCM practices are more likely to come from small, innovative and socially-driven firms rather than larger, market leading manufacturers (Shevchenko et al., 2016). Yet the potential of small firms to change the prevailing practices are severely hampered by resource constraints and 
limited market share. 3DP may offer a means to overcome these constraints (Minetola and Eyers, 2018).

Research on 3DP and market entry offers several competing scenarios. Where customers value variety, the use of $3 \mathrm{DP}$ can give an important advantage to a challenger, potentially forcing the incumbent to exit the market (Hartl and Kort, 2017). If the incumbents adopt 3DP, however, the expectation is that economies of scale (in production) and scope (in marketing and procurement) would make it difficult for new entrants to compete (Weller et al., 2015). To date, such predictions have not been empirically tested. Although there is evidence that 3DP can be rapidly adopted in an industry, for example hearing aids (D'Aveni et al., 2015), in such cases the technology is adopted by the incumbents not entrants.

Additionally, while the possibilities for consumer 3DP have been discussed (Anderson, 2012; Fox, 2014; Bogers et al., 2016), the impact this may have on market entry has not yet been seen.

3DP allows firms to engage with their customers, for example allowing more customised and personalised products (Bogers et al., 2016; Steenhuis and Pretorius, 2016). The digital nature of 3DP makes it possible for small firms to share resources (De Jong and De Bruijn, 2013; D’Aveni, 2015) and innovate more efficiently (Schniederjans et al., 2017; Rindfleisch et al., 2017). It also opens possibilities for customers to contribute through open design (Raasch et al., 2009; West and Kuk, 2016; Chan et al., 2018; Dalenogare et al., 2018) and by supporting the maker movement (Anderson, 2012; Waller and Fawcett, 2014; Halbinger, 2018). 3DP may help change the relationship between producers and consumers, such that firms support customers who design and potentially produce products (van Abel et al., 2011; Chan et al., 2018). To date, no context has been identified in which such predictions have been empirically tested. 
In summary, two barriers to social sustainability in supply chains can be identified from literature. Firstly, the distance between consumption and production means that consumers lack awareness of social sustainability and hence are unlikely to demand improvements. Secondly, while small, innovative, new entrants may be most likely to emphasise social sustainability, they lack the resources to challenge market leaders and hence influence supply chains. The aim of the research is to investigate whether and how 3DP may help overcome both barriers. We therefore pose the following research question:

RQ: How do 3DP and open design compensate for resource constraints when a small firm enters an established market with the aim of promoting socially sustainable SCI?

We propose the mechanism by which 3DP overcomes these barriers relates to open design. Open design engages consumers in a way that reduces their distance from the supply chain and hence can allow them to better appreciate and respond to the sustainability issues. It also leverages consumers' time and intellectual resources, which may compensate for firms' resource shortages. However, the interactions between the constructs of interest are complex and difficult to investigate. To this end, we apply a system dynamics approach. This method allows the complex interactions of multiple factors such as the decisions and responses of consumers and competitors, to be accounted for in creating possible future scenarios. The results suggest that 3DP enabled open design can indeed help a new firm to improve social sustainability in a supply chain, and the system dynamics method allows explanation of the mechanisms by which this occurs.

We investigate the case of Fairphone, a Dutch start-up firm that seeks to introduce innovation in the mobile phone supply chain through an emphasis on fairness and transparency (Chen and Slotnick, 2015). It has also sought to use open design and 3DP to engage consumers in order to achieve its sustainability goals. Fairphone therefore offers a useful setting in which 
to investigate sustainability, 3DP and open design. The remainder of the paper is structured as follows. Section 2 sets out the background by introducing supply chain innovation, sustainable supply chain innovation, 3DP and open design. These concepts are connected in the systems dynamics model, which examines how 3DP enables customers concerned with sustainability to benefit from the efforts of individuals who use open design to create printable phone accessories. Section 3 explains how system dynamics is used as a modelling tool and describes the Fairphone research setting. Section 4 describes the model, drawing on innovation diffusion and open source innovation theories to present three categories of customers, whom we term Fairness, Openness and Regular customers. The model parameters are explained and aligned with empirical data on Fairphone's sales and performance, before the scenario dependent parameters related to 3DP and sustainability are explained. The findings are presented in section 5 and discussed in section 6 in relation to theory and practice. The study makes three contributions to knowledge. Firstly, it provides evidence that small, firms offering socially sustainable supply chain innovation (SCI) can achieve market penetration - in this case, Fairphone is now offered alongside more established brands, by a number of mobile phone network operators because sales have reached a sufficient level. We propose this can lead to wider diffusion of socially sustainable SCI as a defence by incumbents who otherwise have limited incentive for sustainability. Secondly, it demonstrates the influence that early adopters have on the diffusion of socially sustainable SCI in an established supply chain. Our findings suggest that the societal climate towards sustainability, i.e. how many people are sufficiently concerned to buy sustainable products, has a pivotal role in determining whether widespread adoption of SCI is realised. Finally, we make a contribution to the understanding of 3DP. Our findings demonstrate that consumer 3DP may support market entry when small firms leverage open design to overcome their resource constraints. 


\subsection{Background}

\subsection{Supply Chain Innovation}

Supply chain innovation (SCI) has been broadly defined as "a change (incremental or radical) within the supply chain network, supply chain technology, or supply chain processes (or combinations of these) that can take place... in order to enhance new value creation for the stakeholder" (Arlbjørn et al., 2011, p.8). Thereby, extant research has explicated that the elements of supply chain innovation — supply chain network structure, supply chain technology, and supply chain business processes - are interrelated (Munksgaard et al., 2014). As an outcome, supply chain innovation is directed towards increasing competitiveness, customer service, and broader stakeholder value (e.g., Krabbe, 2007; Isaksson et al., 2010; Kwak et al., 2018).

SCIs have had considerable impact on modern economies. Yet compared to technological innovations, there are fewer studies of SCI, particularly how they are adopted and replace dominant SCM practices. Some SCIs are mainly technology driven, for example using drones to deliver parcels or Radio Frequency Identification (RFID) to track shipments (e.g., Jie et al., 2019). More often, however, they are predominantly driven by identification of customers' and other stakeholders' unmet needs that can be satisfied with existing technologies (e.g., Flint, 2005). Companies including Ikea and Dell have generated novel business models that are SCI driven, by eliminating, adding or optimising activities in the supply chain (Abdelkafi and Pero, 2018). Additionally, business model innovations often have widespread impacts but depend upon SCIs to address resulting operational needs. For example, Swift and Company innovated meat-packing in the USA by shipping meat in refrigerated train carriages, rather than livestock for slaughter and Sea-Land Industries' introduction of 
standard containers helped bring about the era of globalisation (Teece, 2010). More recently, a lack of banking infrastructure in Kenya led to the use of mobile phones for banking by MPesa (Crane and Matten, 2016). In each of these cases, the innovation became widely adopted and changed the prevailing supply chain management, to the benefit of customers.

\subsection{Sustainable Supply Chain Innovation}

Sustainable SCI may involve novelty in distribution or in contractual relationships with suppliers to create value for stakeholders. A case in point is the increasing market penetration of fair-trade products, which comes despite challenges such as limited store promotion, consumer awareness, limited product range, fragmented supply and higher costs (Jones et al., 2003; Maloni and Brown, 2006). Fair-trade aims to increase the proportion of revenue that goes to suppliers, such as poor farmers, which by definition, reduces revenues downstream (Porter and Kramer, 2011).

As fair-trade labelling has become more mainstream in some product categories, customers not only expect such labels (Maloni and Brown, 2006), but demand equivalent performance and pricing to mainstream products (Karjalainen and Moxham, 2013). Nonetheless, while consumers expect vulnerable suppliers to be treated fairly, they may not reward such practice since price often dominates purchasing decisions. Fair-trade producers are thus challenged to improve operational performance, while being hampered by the costs associated with fair practices and limited by resource constraints and comparatively lower volumes. Additionally, while sustainable SCIs such as stricter supplier requirements can help the competitiveness of brands associated with fairness, such innovations - unlike product and process innovations are rather easily imitated, particularly if suppliers are shared by competing firms. For 
example, fair-trade labelled cocoa and coffee, once considered niche products, are increasingly adopted by market leaders such as Mars and Nestle.

Yet despite arguments that social responsibility may contribute to supply chain performance, many firms fail to adopt socially responsible practices unless forced by stakeholder pressure (Eltantawy, 2016). In stakeholder theory, the salience and power of stakeholders are particularly important factors (Hoejmose et al., 2013). Salience is the extent to which managers are aware of and concerned about particular stakeholder groups. If consumers concerned with social responsibility are - or are perceived to be - a minority, then their concerns are less likely to influence managerial decisions (Shevchenko et al., 2016). Power, on the other hand, concerns the extent of influence that stakeholders have and the bargaining position that allows buyers or suppliers to determine priorities. A recognised weakness of stakeholder theory is the difficulty in defining who are legitimate stakeholders whose concerns should be acted upon (Mitchell et al., 1997). Where stakeholders hold little power, supply chains may not embrace their claims for more sustainable production practices, for example tackling child work in mines (Hofmann et al., 2018). Hoejmose et al. (2013) state that it is typically a combination of pressure from consumers and legislation from governments that drives socially responsible supply chain practices upstream in the supply chain. In our model we refer to this combined effect as the Societal Climate towards Sustainability. These practices are seen to carry a cost, so that a trade-off between cost and reputation drives decisions such as disclosure of sources, selection of ethical sources (Chen and Slotnick, 2015) and sustainable supplier development (Yawar and Seuring, 2017). In the next sections, we consider how 3DP may be connected to sustainable SCI.

\subsection{D Printing in Supply Chain Management}


The term 3DP, also known as additive manufacturing (AM), refers to a collection of methods that build objects in layers of plastic, metal or other material, directly from digital design files (Petrovic et al., 2011; Mellor et al., 2014; Holmström and Partanen, 2014). This definition captures a broad spectrum of processes and technologies, most of which use light or heat to create physical objects from metal or polymer materials, under computer control (Weller et al., 2015). Production with almost no geometric restrictions on the product and almost no geographical restrictions on place, with minimal wasted material and no cost penalty for low volumes has fuelled predictions of a new industrial revolution (Petrovic et al., 2011; Huang et al., 2013).

Initially developed for producing prototypes in the 1980s (Beltagui et al., forthcoming), industry research suggests a steady growth of 3DP use in production of end-use parts (D’Aveni, 2015; Bandyopadhyay et al., 2015; Li et al., 2017; Schniederjans et al., 2017; Candi and Beltagui, 2019). 3DP is now used to produce motorsports parts, where the lack of tooling allows one-off production, on demand. Medical implants such as hip replacements can be printed, with the digital design customised to fit a digital scan of the patient. Aircraft engine fuel nozzles have been redesigned to consolidate a sub-assembly into a single component that is impossible to produce by traditional means. 3DP has been tested in the spare parts supply chain for military aircraft (Khajavi et al., 2014). Beyond these niche industrial applications, however, the development of low-cost printers has generated hype and even captured the imagination of politicians (Barnatt, 2013; Weller et al., 2015). Consumer grade 3D printers are available for under US \$1,000 and are even offered in some supermarkets. ${ }^{1}$ The availability of such printers can be traced to the expiry of the earliest 3DP

\footnotetext{
${ }^{1}$ https://www.aldi.co.uk/balco-3d-printer/p/086887240233900?gclid=EAIaIQobChMIpN2ilpbc3wIViJPtCh1wfgGAEAAYASAAEgJuWfD_BwE\&gclsrc=aw.ds last accessed 7th January, 2019.

(C) 2019. This manuscript version is made available under the CC-BY-NC-ND 4.0 license (http://creativecommons.org/licenses/by-nc-nd/4.0/)
} 
patents, which enabled the RepRap project, an attempt to create 'self-replicating' printers (Raasch et al., 2009). While it remains unlikely that every home will possess such a printer, their connectivity means they may be easily shared by several consumers or businesses (D’Aveni, 2015). Online communities such as thingiverse allow designs to be shared and downloaded for 3DP (West and Kuk, 2016). And platforms such as 3D Hubs allow individuals to advertise available 3DP capacity, so that others may locate and commission 3DP services. Combining such offerings means that individual consumers may design, manufacture or both. As a result, consumers possess the means to create innovative products, which increases the potential of open design.

\subsection{D Printing and Open Design}

The term open design refers to "free revealing of information on a new design with the intention of collaborative development of a single design or a limited number of related designs for market or nonmarket exploitation” (Raasch et al., 2009, p.383). It is founded on the private-collective model observed in open source innovation (von Hippel and von Krogh, 2003). Innovation increasingly originates not in R\&D labs, but from external sources including customers (Zhang et al., 2016). And the term open source was coined to describe the development of software through the voluntary and collective effort of users or other private citizens, who freely reveal the source code behind the software they develop (Lakhani and von Hippel, 2003). The so-called maker movement sees these practices applied to the design of physical goods, as opposed to digital software and is a phenomenon closely associated with 3DP (Waller and Fawcett, 2014).

Anderson (2012) suggests that humans are inherently predisposed to making, which some express through activities such as gardening or cooking, but that the increasingly digital nature of life and work limits exposure to physical making. Part of the appeal of 3DP, 
therefore, is that it allows would-be makers to move from digital design to physical production, to make and repair rather than passively consume (Fox, 2014). Studies of makers have focused on physical communities such as Fablabs (Walter-Hermann, 2013) or makerspaces (Halbinger, 2018) as well as online communities that practice open design in a similar manner to open source software communities. The appeal of such communities lies not in financial gain, but in the opportunities for skills development and social interaction (Nambisan and Baron, 2009).

Open design therefore represents an important source of innovation for manufacturers that are able to engage such communities (Van Abel et al., 2011), while maintaining the spirit of openness that drives them (West and Kuk, 2016). For small firms, seeking to introduce SCIs into established markets, harnessing the power of the maker movement may offer a means of overcoming limited resources. In the following sections we explain the methods used to examine this proposition using the case of Fairphone.

\subsection{Methodology}

In this section we first explain the overall research setting, and then justify the case selection (Fairphone) and choice of system dynamics as modelling tool, before the subsequent section provides details regarding model development and description.

\subsection{Research Setting}

We selected Fairphone as the research setting because it allows an investigation of both social sustainability and open design. Fairphone is a start-up firm based in the Netherlands, producing phones using a modular design that can be customised, repaired and updated, in order to be fairer to customers. Similar to proponents of the open source software movement, 
this stems from a belief that access to the product should not be restricted by physical or legal barriers (TEDx, 2013). This contrasts strongly with the industry's current practices, such as use of proprietary software, non-removable batteries and even screws that require a proprietary screwdriver.

In its supply chain design, Fairphone emphasises fairness to workers. This begins with transparency, for example providing a detailed breakdown of how the price of a product is distributed, as well as disclosure over which suppliers are used. A portion of revenue is donated to a worker managed fund to improve workplace conditions at suppliers' factories, while Fairphone has a commitment to ensure no conflict minerals are used in its phones. Sales of 5,000 units for the first batch of Fairphone product demonstrate that there is demand for a sustainably produced smart phone. However, this demand is confined to a relatively small segment that we refer to as Fairness Customers, who are attracted by the firm's commitment to social sustainability. Appealing only to this group restricts the degree to which Fairphone can achieve its aim of making mobile phone supply chains in general more sustainable. Mainstream consumers are less inclined to pay more for a brand they perceive as more ethical.

Using 3DP, Fairphone is able to target a second group of consumers, whom we refer to as Openness Customers by facilitating open design of accessories for its product. This began with a design competition in 2014 in which four phone covers were created by users, with the electronic design files available to download and 3D print. Subsequently, a range of userdesigned accessories were made available for customers to purchase, download and print locally. Openness consumers may be motivated by the opportunity to apply their creativity to the development of complementary products, which may enhance Fairphone's appeal to other customers. The increased availability of accessories in turn helps Fairphone to capture a 
greater market share by appealing to mainstream consumers and thereby develop a stronger influence over the supply chain. 3DP has therefore enabled Fairphone to overcome the challenge of limited availability of accessories, which are typically produced in mass volume production lines.

Our simulation model analyses how the sharing of design files and ultimately the production of accessories through 3DP has enabled Fairphone to increase sales and become a respected player in a market dominated by existing manufacturers producing high volumes. Using 3DP has allowed Fairphone to offer a large variety of accessories that would otherwise have been impossible to produce given the limited initial production volumes.

\subsection{System Dynamics as a Modelling Tool}

We selected system dynamics methodology for the following reasons. First, system dynamics allows modelling of feedback loops, of which there are several in the case of Fairphone. Second, our model includes a number of stock variables that are increased or decreased at each period. The number of customers is a typical stock variable, which increases or decreases over time depending on the firm's actions. Some effects, like the adoption of Fairphone products by mobile network operators, occur only once a specific number of customers is reached. Such thresholds can only be studied through dynamic models over multiple periods. Third, a number of functions in the model are non-linear, such as the Sshaped curve describing 3DP adoption. Such functions are particularly suitable for modelling with system dynamics (Sterman, 2000). Finally, system dynamics is especially useful for analysing the outcomes of different scenarios, by varying parameters in order to compare their effect on the system in a risk free environment (Santos et al., 2002). System dynamics is 
therefore appreciated by managers because it facilitates brainstorming (Jahangirian et al., 2010).

System dynamics has been widely used in similar studies. For example, Reiner et al. (2015) analyse how contextual variables affect economic viability and social performance of a social business targeting the poor as consumers, employees, suppliers and distributors. Abdelkafi and Täuscher (2015) represent a business model for sustainability with a system dynamics model, featuring a number of reinforcing feedback loops that create value for the customer, the firm and the environment. Li et al. (2017) used system dynamics to compare spare parts supply chain with and without 3DP. Finally, in the field of humanitarian logistics and disaster management, Kunz et al. (2014) used this simulation tool to compare the outcome of different scenarios, as we do in this paper.

\subsection{Simulation Approach}

We developed the Fairphone system dynamics model based on empirical data including news and industry reports, Fairphone's website, and the experience of one author as a customer. Our model simulates the cumulative number of Fairphone customers as a function of time and variables input parameters. We started building the model 52 months (4.3 years) after Fairphone began production, when the milestone of 135,000 customers had been reached. It replicates the sales of Fairphone during the first four years of the company's existence, and estimates expected sales for the subsequent years.

We use our model to show how 3D printing contributed to Fairphone's growth from a small batch production targeting a niche market (initially 5,000 units produced in 2013) to an established phone brand sold by several mobile network operators across Europe. The model also shows how Fairphone might become a mainstream product carried by multiple large 
network operators, thus taking a prominent position in the mobile phone industry and inducing change among other manufacturer through its social sustainability practices.

\subsection{Model}

\subsection{Model description}

Due to space constraints and the complexity of the model, we will describe the model in general terms and focus only on variables of particular interest. Appendix A shows the full model, while a simplified view is presented in Figure 1.

The number of customers of a firm is a good proxy for its growth and performance. We therefore model the number of Fairphone customers, i.e. purchasers of phones, over time. Figure 1 presents a simplified view of our model, which we will describe in more detail in the following subsections. The grey field shows all Fairphone customers, which is the sum of three types of customers, Fairness Customers, Openness Customers and Regular Customers. Each of these customer groups is represented in green in Figure 1. The yellow fields represent the variable parameters of our model. Table 1 describes the variables used in the model. 


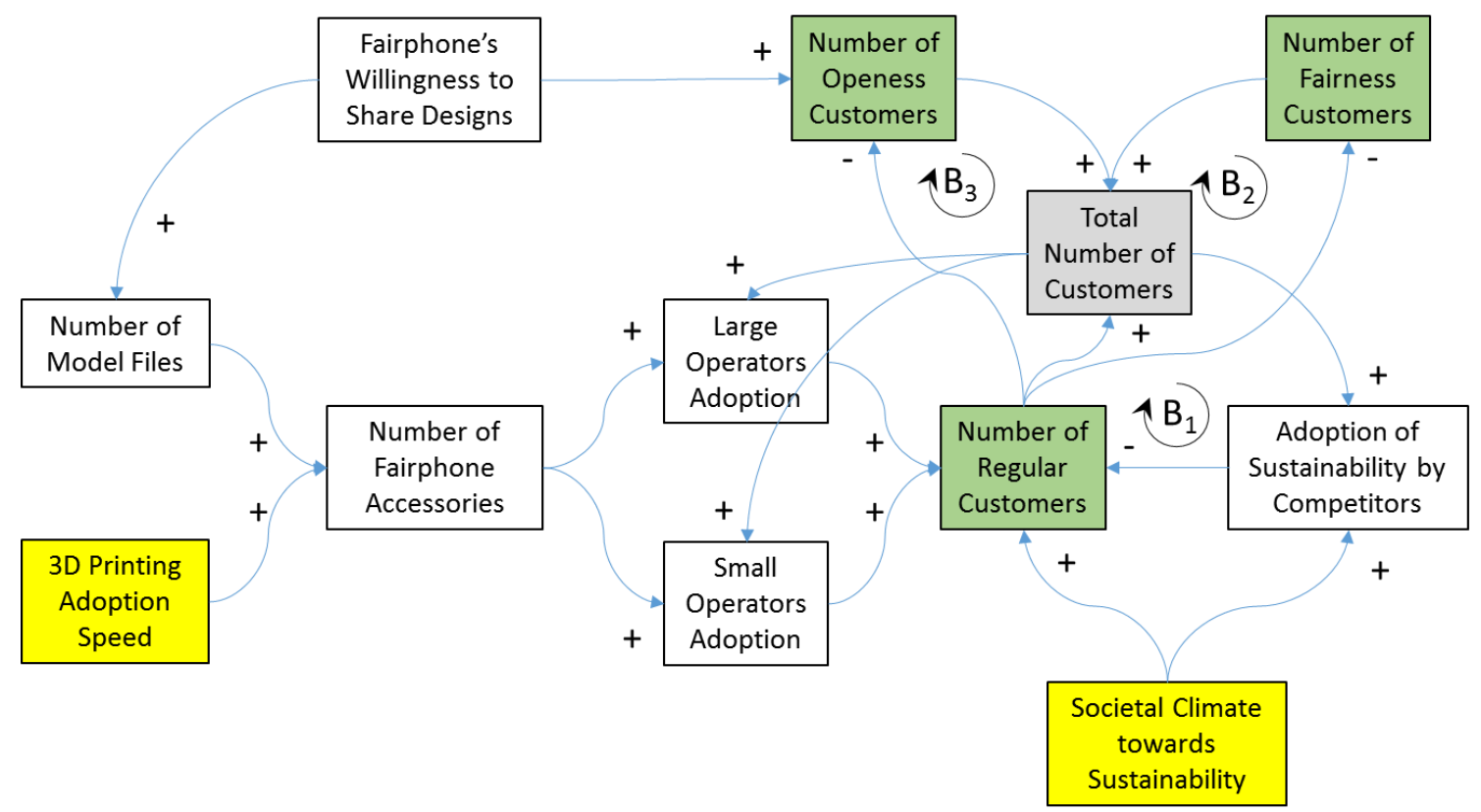

Figure 1 - Simplified view of System Dynamics model 
Table 1 - Description of variables used in simplified model

\begin{tabular}{|c|c|}
\hline Variable & Description \\
\hline Number of Fairness Customers & $\begin{array}{l}\text { Cumulative number of customers attracted by } \\
\text { Fairphone's socially responsibly supply chain }\end{array}$ \\
\hline Number of Openness Customers & $\begin{array}{l}\text { Cumulative number of customers attracted by } \\
\text { Fairphone's openness philosophy }\end{array}$ \\
\hline Number of Regular Customers & $\begin{array}{l}\text { Cumulative number of customers who buy the Fairphone } \\
\text { because it is offered through network operators }\end{array}$ \\
\hline Total Number of Customers & $\begin{array}{l}\text { Sum of all types of customers (Fairness, Openness and } \\
\text { Regular) }\end{array}$ \\
\hline 3D Printing Adoption Speed & $\begin{array}{l}\text { Parameter defining how fast 3D printing will be adopted } \\
\text { by society }\end{array}$ \\
\hline $\begin{array}{l}\text { Societal Climate towards } \\
\text { Sustainability }\end{array}$ & $\begin{array}{l}\text { Parameter defining degree to which mainstream } \\
\text { consumers' buying decisions are influenced by } \\
\text { sustainability values }\end{array}$ \\
\hline $\begin{array}{l}\text { Fairphone's Willingness to } \\
\text { Share Designs }\end{array}$ & $\begin{array}{l}\text { Fairphone's decision to share designs of its phone to } \\
\text { enable users to design and 3D print accessories }\end{array}$ \\
\hline Number of Model Files & $\begin{array}{l}\text { Number of different files available for customers to print } \\
\text { their accessories }\end{array}$ \\
\hline $\begin{array}{l}\text { Number of Fairphone } \\
\text { Accessories }\end{array}$ & $\begin{array}{l}\text { Number of different accessories available for Fairphone } \\
\text { (function of 3D printing adoption) }\end{array}$ \\
\hline Small Operators Adoption & $\begin{array}{l}\text { Adoption level of Fairphone by small network operators, } \\
\text { depends on cumulative sales and availability of } \\
\text { accessories }\end{array}$ \\
\hline Large Operators Adoption & $\begin{array}{l}\text { Adoption level of Fairphone by large network operators, } \\
\text { depends on cumulative sales and availability of } \\
\text { accessories }\end{array}$ \\
\hline $\begin{array}{l}\text { Adoption of Sustainability by } \\
\text { Competitors }\end{array}$ & $\begin{array}{l}\text { Competitors' level of adoption of sustainable supply } \\
\text { chain practices }\end{array}$ \\
\hline
\end{tabular}

\subsubsection{Fairness Customers}

Fairness Customers are the first customers to buy the Fairphone, because of its niche proposition of being produced through a socially responsibly supply chain. In the innovation diffusion model (Rogers, 2003), these customers are the typical innovators and early adopters who play an important role in the purchase decision of future customers. There are 5,000 initial customers of this type, which represents the customers who pre-ordered the first batch 
of Fairphone before it was produced (June 2013, $\mathrm{t}=0$ ). These customers are motivated by the vision of Fairphone and they increase at a constant rate of 1,920 customers per month (historical average calculated based on Fairphone's sales). These customers decrease as the number of Regular Customers increases because they become Regular Customers (i.e., buy the phone from network operators) or leave the brand because it is no longer a niche product (see balancing feedback loop $\mathrm{B}_{2}$ in Figure 1).

\subsubsection{Openness Customers}

Openness Customers buy the phone because they like Fairphone's philosophy of openness, particularly the availability of design files to allow customers to design accessories. In this sense, they are comparable to customers attracted by open source products in the software industry. We therefore used the market share of an open source web browser (Mozilla, $13.29 \%^{2}$ ) to define the portion of Openness Customers compared to Fairness Customers. Openness Customers are innovators and early adopters in the innovation diffusion model (Rogers, 2003). These customers started buying Fairphone when it made the files available 13 months after the launch ${ }^{3}$ (parameter Delay until Fairphone Starts Sharing Designs).

Fairphone's willingness to share designs combined with the increase in Openness Customers leads to the design of accessory files by the community. In July 2014, Fairphone for example launched a design competition for phone cases. It shared the design files of the phone so that designers in the community could design accessories. The winning designs are displayed on Fairphone's website and available as free download. The subsequent increase in accessories designed by the community allows a range of complementary products to be sold. These are

\footnotetext{
${ }^{2}$ https://www.netmarketshare.com/browser-market-share.aspx

${ }^{3}$ https://www.fairphone.com/en/2014/07/07/launching-fairphone-3d-printed-cases-with-3d-hubs/

(C) 2019. This manuscript version is made available under the CC-BY-NC-ND 4.0 license (http://creativecommons.org/licenses/by-nc-nd/4.0/)
} 
available as digital models that can be produced on the customer's own printer or through 3D Hubs, a worldwide network of 3DP service providers. ${ }^{4}$ Combined with the increased number of $3 \mathrm{D}$ printers in use, this led to an increased availability of accessories.

The low initial volumes and limited resources mean Fairphone could not feasibly produce accessories, nor would third parties produce them due to limited demand. Accessories such as protective cases are nonetheless important for mobile phone users and may be viewed as order qualifiers for some customers. A brand that does not offer such accessories would therefore be disadvantaged. This is especially true for Fairphone, which sold its phones exclusively over the internet until the product was adopted by small network operators. Offering customers the option to buy accessories over its website when ordering a phone was therefore particularly important. Using 3DP enabled Fairphone to offer a large variety of accessories (including different designs and colours) while sales volumes were low, without requiring high investments such as injection moulding tooling used for mass production (Minetola and Eyers, 2018). The availability of accessories was also a criterion for the decision of small network operators to adopt the Fairphone. Not only do accessories represent an important source of income for network operators selling the phone in their shops, but they also respond to the practical and experiential needs of customers. Openness Customers therefore played an important role in the growth of Fairphone by designing accessories and sharing them over the internet.

In December 2017 (Month 55, 4.5 years after start of production), Fairphone announced the end of its policy of sharing model files to be $3 \mathrm{D}$ printed. ${ }^{5}$ This decision was due to operational issues with the 3D Hubs network, not a sudden change in its open business

\footnotetext{
${ }^{4}$ https://www.fairphone.com/en/2014/07/07/launching-fairphone-3d-printed-cases-with-3d-hubs/

${ }^{5} \mathrm{https} / / /$ forum.fairphone.com/t/3d-printed-accesories-are-no-longer-available/36069 
model. Nevertheless, from this point Fairphone did no longer actively promote 3D printed accessories on its website, and because of this decision, the number of Openness Customers started to shrink. This led to a slowdown in the number of accessories designed and produced through 3D printing, and the firm started offering non-3D printed accessories. Since the number of accessories available at this time was already substantial (around 1,200), the decision did not strongly limit Fairphone's growth.

In addition to Fairphone's decision, Openness Customers also start to leave the brand as the number of Regular Customers increases, because it is no longer a niche product (balancing feedback loop $\mathrm{B}_{3}$ in Figure 1).

\subsubsection{Regular Customers}

The third segment are Regular Customers, who buy the Fairphone once it is offered by mobile network operators. These customers are the early majority customers in the innovation diffusion model (Rogers, 2003). They choose the product among a selection of other phone brands when renewing their subscription, for reasons not necessarily related to sustainability. Network operators are crucial actors in the mobile phone market, since customers mainly purchase their phones in combination with a subscription renewal. Because network operators have access to a large pool of customers, they will have a crucial role in helping Fairphone become a mainstream mobile phone brand.

In order for mobile network operators to adopt the Fairphone in their assortment, we consider two important conditions. First, Fairphone must offer a number of accessories, in particular protective accessories like phone cases. Second, the total number of existing customers must exceed a specific threshold, otherwise the operator cannot achieve required volume and profitability. We see this adoption as a two-step process. Once a sufficient number of accessories was available through 3DP (Adoption Threshold Accessories Small Operators) 
and the number of Fairness Customers together with Openness Customers reached a certain threshold (Adoption Threshold Sales Small Operators), small network operators added the phone to their assortment. This is similar to small supermarket chains who started adopting fair-trade coffee and chocolate at the beginning of the fair-trade movement in the early 1990s (Low and Davenport, 2006). The adoption of Fairphone by small operators was observed when Swisscom and T-Mobile Austria adopted the phone in March $2016(t=34)$. Small Operators are those who realised the potential of Fairphone early on and decided to offer it to their customers as a niche product. These operators are either niche operators in large markets (e.g., the Phone Co-op in the UK), or hold a large market share in small markets (e.g., Swisscom in Switzerland). In other words, small operators are those who do not have a dominant position in the global European market.

The adoption of Fairphone by small operators led to an increase in Regular Customers. We anticipate that once the number of customers reaches a higher threshold (Adoption Threshold Sales Large Operators), large operators will add the phone to their assortment as well, similar to large agri-food brands who added fair-trade products to their offerings because they saw a significant demand and a growth opportunity (Levi and Linton, 2003; Davies, 2007). These operators have a significant market share and a dominant position in the European market. Due to their access to a large pool of customers, these operators have the potential to make the number of Fairphone customers grow at a faster rate. This rate will depend on the parameter Societal Climate towards Sustainability. The large network operators will be key in making Fairphone become a mainstream brand in the mobile phone market.

As the number of Regular Customers increases and Fairphone gains market shares, we expect competitors of Fairphone to react by adopting sustainability practices in their supply chain in order to tap into Fairphone's customers interested in sustainability. This has been observed in 
other contexts in which large incumbents react to the threat of new entrants by imitating sustainable innovations (Hockerts and Wüstenhagen, 2010). The speed of this reaction by competitors is defined by the parameter Societal Climate towards Sustainability. This effect will fulfil the initial vision of Fairphone, i.e., to bring sustainability practices to electronics supply chains. It will however also have a negative effect on sales of Fairphone, because customers who were initially attracted to Fairphone because of its sustainability practices may start leaving the brand and buy competing products (see arrow with negative sign between Adoption of Sustainability Practices and Number of Regular Customers). This effect is the result of a balancing feedback loop (see $\mathrm{B}_{1}$ in Figure 1) that will ultimately stabilise Fairphone's market share.

\subsection{Selection of Parameters}

A system dynamics model consists of parameters and equations. Most of the parameters are based on empirical data and are therefore constant. These constants were identified based on company reports, websites and industry news. The parameters defining the growth of Openness Customers and Fairness Customers were defined in order to replicate the observed cumulative sales reported by Fairphone during the first 52 months of operation (4.3 years). Table 2 presents the timeline of these first months with major events and cumulative sales figures.

Table 2: Timeline of Fairphone sales

\begin{tabular}{llll}
\hline Date & Month \# & $\begin{array}{l}\text { Cumulative sales } \\
\text { all customers }\end{array}$ & Remark \\
\hline June 2013 & 1 & 5,000 & $\begin{array}{l}\text { Preorders of first batch of } \\
\text { Fairphone 1 start. Production } \\
\text { starts. }\end{array}$ \\
January 2014 & 8 & 25,000 & \\
May 2014 & 12 & 37,000 &
\end{tabular}


June 2014

Fairphone makes model file of phone available to allow customers to design accessories.

July $2015 \quad 26$

December $2015 \quad 31$

March $2016 \quad 34$

December $2016 \quad 43$

September $2017 \quad 52$

December $2017 \quad 55$
Preorders of Fairphone 2 start.

First Fairphone 2 delivered.

Swisscom \& T-Mobile Austria adopt the Fairphone as first small network operators.

Fairphone stops offering design

files of accessories on its website.

Figure 2 shows the results of our simulation model in comparison with the observed data

from Table 2. The modelled values demonstrate a close fit with the empirical data points, featuring some small deviations that may be due to factors not captured by the simulation (e.g., negative news reports about poor working conditions in electronic supply chains, advertising by Fairphone, positive or negative user experience shared on social media and forums).

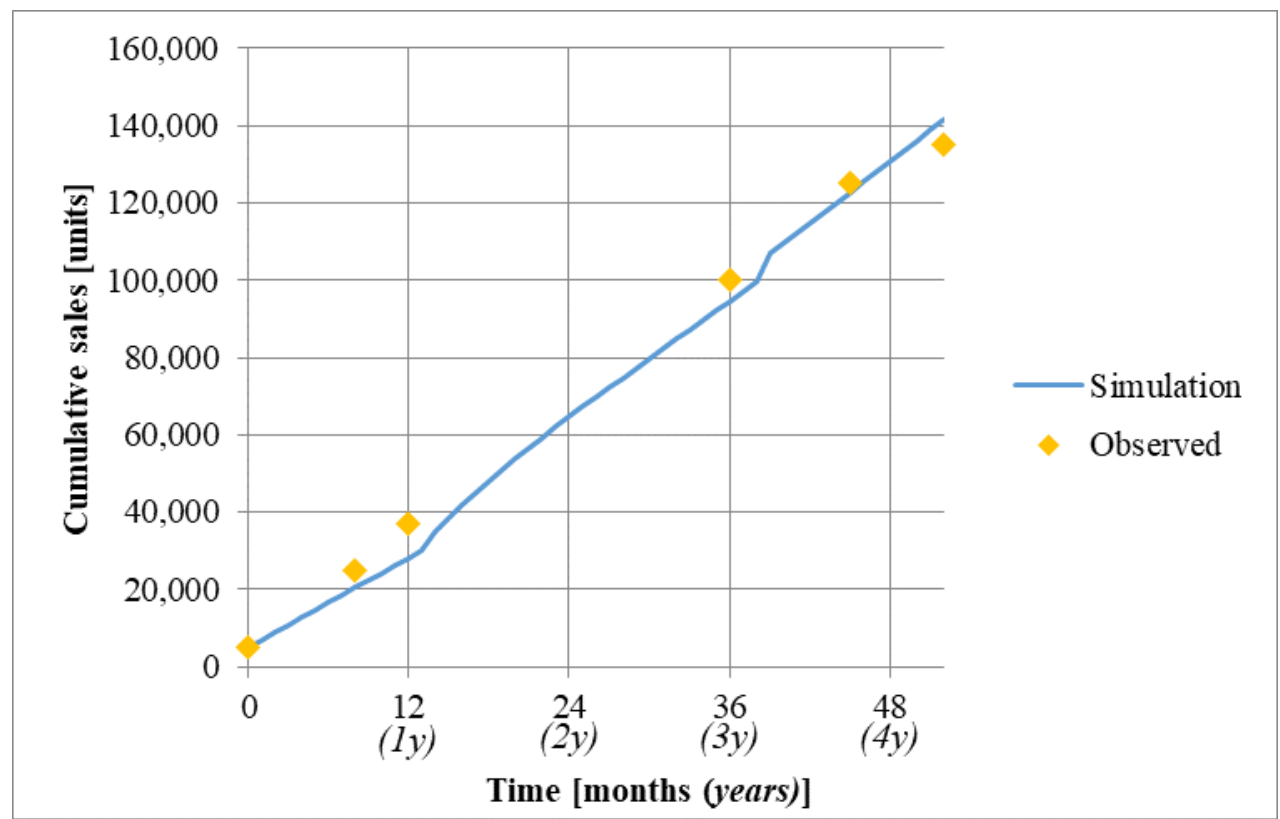

\footnotetext{
${ }^{6}$ Interpolation based on other values

${ }^{7}$ https://www.fairphone.com/wp-content/uploads/2016/12/Fairphone_Shortmailing_Mobilcom-Shops-1.pdf

${ }^{8}$ https://www.fairphone.com/wp-content/uploads/2017/09/Press-Release_Investment_and_MD-1.pdf 
Figure 2 - Number of customers of Fairphone, observed data and simulated data

\subsection{Scenario Dependent Parameters}

In addition to the constant parameters described above, there are other parameters that are not constant, and their value can vary in different ways in the future. The adoption rate of a technology, like 3DP in our case, would be a typical example of such variable parameters. The value of system dynamics simulation resides in its ability to compare scenarios with different values of such parameters and analyse a number of resulting what-if alternatives.

Based on our extensive reading of Fairphone's history on the company's website ${ }^{9}$ and user forums, ${ }^{10}$ we identified two variable parameters that are assumed to have an important impact on the increase in Fairphone's customers: 3D Printing Adoption Speed and the Societal Climate towards Sustainability. These parameters are represented in yellow in Figure 1.

We empirically identified the value of these parameters for our base case scenario and validated them by comparing the outcome of the system dynamics model with the sales data reported by Fairphone (Figure 2). We then created additional scenarios in which we increased and decreased these parameters by $50 \%$. Although the values in the base scenario are empirically validated, the increased and decreased parameters are hypothetical and cannot be validated.

\subsubsection{D Printing Adoption Speed}

The 3D Printing Adoption Speed is a parameter that describes how fast 3DP will be adopted by society. 3D Printing Adoption Speed is a normalised parameter varying between 0 and 1 ,

\footnotetext{
${ }^{9}$ https://www.fairphone.com

${ }^{10} \mathrm{https} / / /$ forum.fairphone.com

(C) 2019. This manuscript version is made available under the CC-BY-NC-ND 4.0 license (http://creativecommons.org/licenses/by-nc-nd/4.0/)
} 
and it multiplies the number of model files that are available. A faster 3DP adoption rate means more rapid increase in the number of $3 \mathrm{D}$ printers in use. A feature of 3DP is the ease with which resources can be shared by sending digital files to a nearby printer. This means, if the adoption rate is higher, it becomes easier to access a 3D printer since the likelihood that one will be available in the local area increases. For example, public libraries increasingly provide 3D printers, while the number of makerspaces providing access to 3DP continues to grow and numbers of companies or individuals who may offer their excess capacity are likely to increase. This in turn can lead to greater availability of accessories, which will encourage network operators to offer Fairphone products to their customers.

We vary 3D Printing Adoption Speed by changing the parameter Maximal Fractional Adoption Rate Increase, which determines how fast the adoption rate can increase. The original scenario had a value of 0.12 (validated with our empirical data). We create a scenario $3 D$ Printing Faster in which this value is increased by $50 \%(0.18)$ and a scenario $3 D$ Printing Slower in which this value is decreased by $50 \%(0.06)$.

\subsubsection{Societal Climate towards Sustainability}

The Societal Climate towards Sustainability is a parameter that multiplies the growth rate of Regular Customers as well as the Adoption of Sustainability by Competitors. This suggests the degree to which mainstream consumers' buying decisions are influenced by social sustainability values. The higher this parameter is, the faster the number of Regular Customers will increase. This parameter also influences the adoption of sustainability practices by competitors. The higher this parameter, the faster competitors will adopt these sustainability practices. 
The original scenario has a Societal Climate towards Sustainability of 1 (validated with our empirical data). We create a scenario Sustainable High in which the parameter is increased by $50 \%$ (1.5) and a scenario Sustainable Low in which this parameter is decreased by $50 \%$ $(0.5)$.

\subsection{Findings}

The system dynamics model presented in the previous section enables us to simulate the evolution of the number of Fairphone customers over a long time horizon. We believe that our model simulates the future of Fairphone accurately for two reasons. First, all parameters and variables we used in the model are based on real empirical figures. Second, we have validated the result of our model with the data on Fairphone's expansion so far. Based on the model, we are able to evaluate possible scenarios about the future expansion of Fairphone's number of customers. There are however multiple variables that we do not control which may impact the expansion of Fairphone in different ways.

Since the aim is to understand whether and how 3DP can overcome barriers to social sustainability, the objective of the study is not to predict a specific number of customers, but to understand the mechanisms that may drive change. We achieve this by varying two scenario dependent variables. In this section we first present the results of our simulation for the base case scenario (i.e., the one that leads to the outcome observed at Fairphone so far). We then present the outcome of the other scenarios.

\subsection{Base Case Scenario}

This scenario is the starting point of our model and fits our observations of practice. When it launched the first product, Fairphone started selling to Fairness Customers, and after 13 
months to Openness Customers, which represent innovators and early adopters (Rogers, 2003). These two groups of customers have different motivating factors for buying the Fairphone, but both contribute to the initial growth of sales experienced by the firm during its first three years. This segmentation of early adopter customers into different groups with varying motivating factors has been observed previously in the adoption of sustainable innovation. For the adoption of sustainable energy solutions, Nygren et al. (2015) for example distinguished between four groups of early adopters with different sets of motivators, such as environmental concern, self-sufficiency or economic profit. Similarly, Tran et al. (2013) found that early adopters of alternative fuel vehicles had differing motivations, such as environmental appeal, reliability or new technology.

In our model, Fairness Customers starts with 5,000 first customers who pre-ordered the first batch of Fairphone 1 before it was launched. The number of Fairness Customers then increases until Month 130 (10.8 years), as presented in Figure 3. At this point, the number of Fairness Customers starts to decrease due to the fact that Fairphone becomes more mainstream, and existing Fairness Customers shift to the category Regular Customers who buy the phone through network operators (or switch to other brands that also become more sustainable). Fairness Customers are early adopters that purchased the phone over unconventional distribution channels (crowdsourcing, internet). Once Fairphone becomes available for purchase from usual channels (i.e., shops of network providers), we assume that Fairness Customers become Regular Customers who purchase the phone through these shops as part of their subscription. This effect is represented by the balancing feedback loop $\mathrm{B}_{2}$ in Figure 1.

Openness Customers start with an initial value of 0 . After 13 months, Fairphone makes its design files available online and encourages customers to design accessories that can be 3D 
printed. This immediately attracts interest from the Openness Customers segment, which grows steadily until Month 55 (4.5 years), as represented in Figure 4. At that time, Fairphone stops offering design files of accessories on its website, and as a result the number of Openness Customers starts declining.

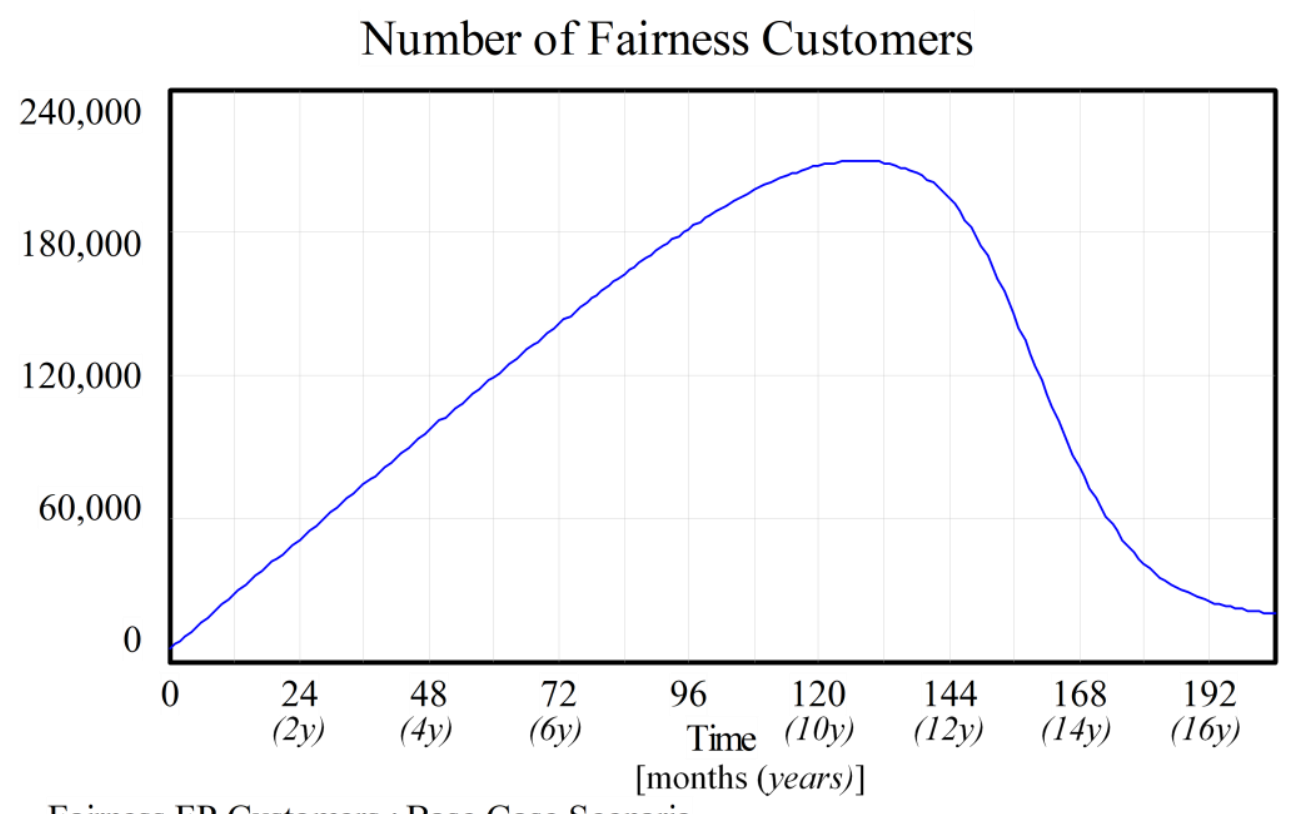

Fairness FP Customers : Base Case Scenario

Figure 3 - Number of Fairness Customers 


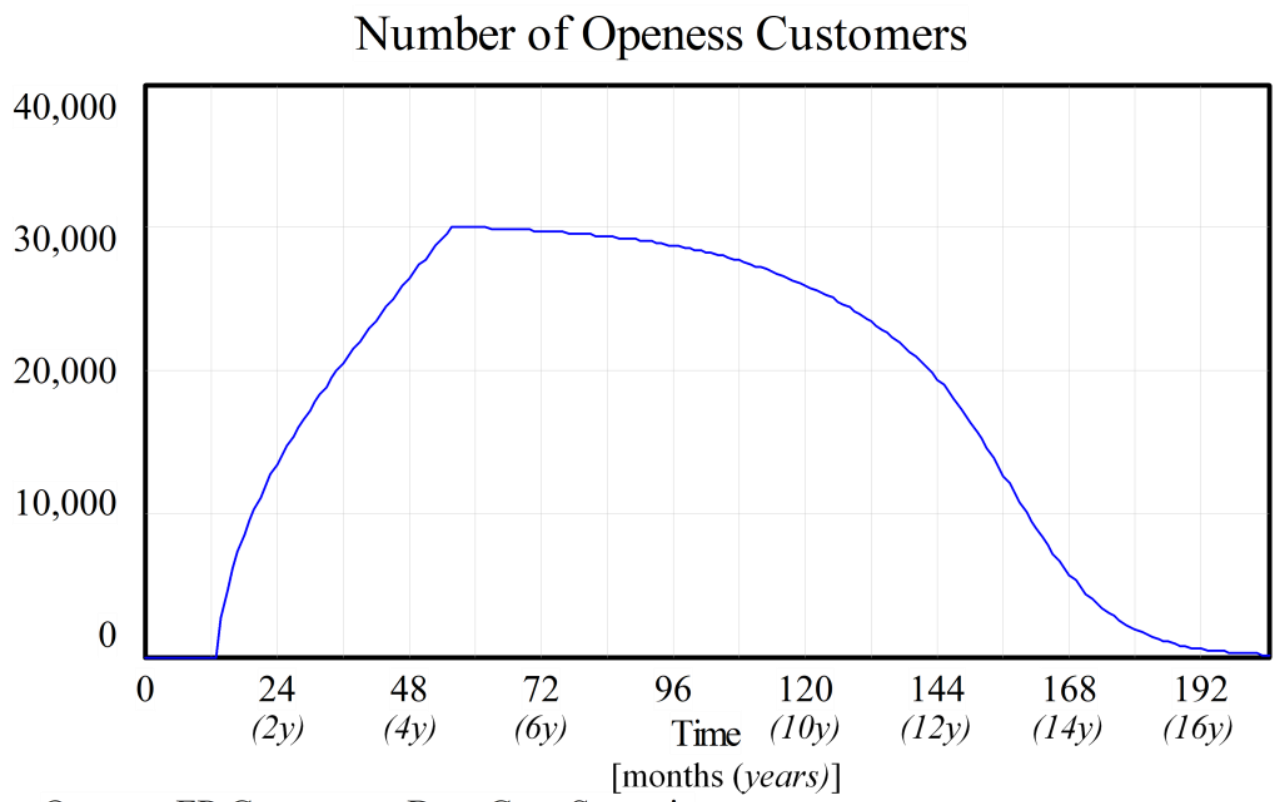

Openess FP Customers : Base Case Scenario

Figure 4 - Number of Openness Customers

In our simulation, we assume that growth of Fairness Customers and Openness Customers will encourage mobile phone network operators to adopt the Fairphone, which will lead to an increase in Regular Customers. Figure 5 shows the increase in Regular Customers, first at a slow rate (when it is offered by small network operators) and then at a faster rate once large network operators include it in their assortment. 


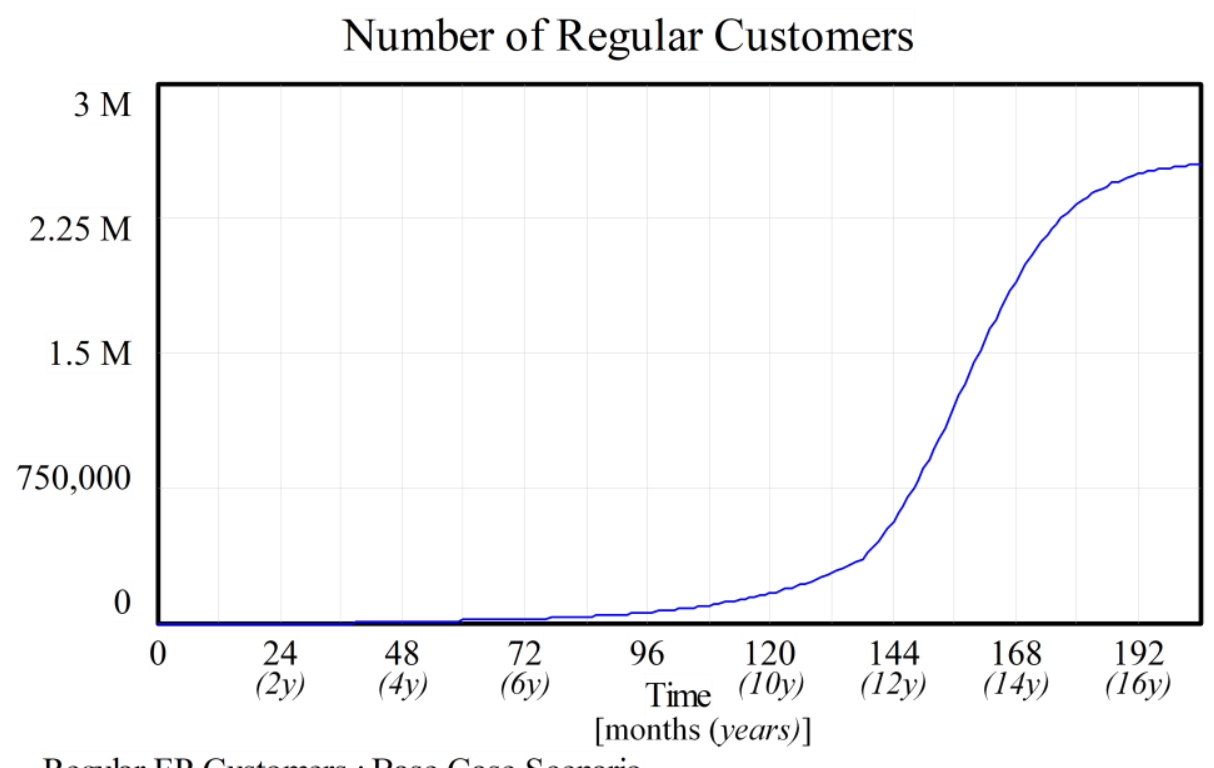

Regular FP Customers : Base Case Scenario

Figure 5 - Number of Regular Customers

Figure 6 shows that the total number of Fairphone customers increases rather slowly until about Month 140 (11.7 years), when large network operators adopt the phone. From that point, the number of customers increases at a faster pace. We expect that the adoption of Fairphone by large network operators and the resulting increase in regular customers will have an impact on the entire market. If Fairphone becomes an important player in the market with substantial sales, there is a greater likelihood that competitors will acknowledge customers' acceptance of Fairphone's principles. As a result, they may adopt similar practices to Fairphone, to attract customers who value sustainability. This balancing feedback loop ( $\mathrm{B}_{1}$ in Figure 1) will in turn cause the market share of Fairphone to stabilise around Month 200 (17 years), as shown in Figure 6. In addition to its commercial success, Fairphone has therefore also achieved its objective of advocating for more sustainable supply chains, by inducing a move towards greater sustainability in electronics supply chains. 


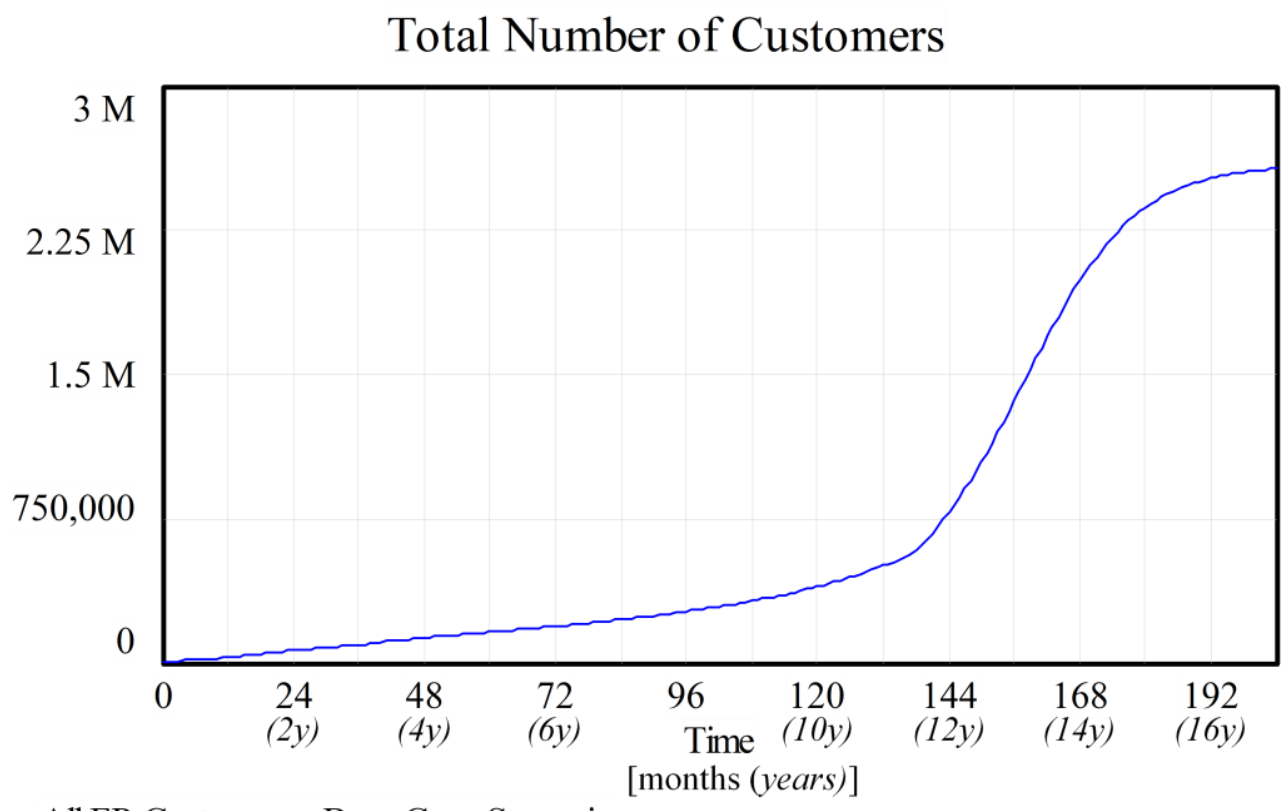

All FP Customers : Base Case Scenario

Figure 6 - Total number of Fairphone customers

\subsection{Scenario Analysis}

We conducted a sensitivity analysis on two important parameters: $3 D$ Printing Adoption Speed and the Societal Climate towards Sustainability. The objective of this analysis is to see how much the success of Fairphone would be impacted if these parameters changed.

\subsubsection{Impact of 3D Printing Adoption Speed}

The 3D Printing Adoption Speed is a parameter that describes how fast 3D printing will be adopted by society. A fast 3D printing adoption will lead to faster availability of accessories, which is a criterion for the adoption of Fairphone by small network operators. In addition to the base case scenario (which has been validated by empirical data), we run one hypothetical scenario in which the adoption speed is faster (3DP Faster) and one in which the adoption is slower (3DP Slower). The resulting 3D printing adoption is shown in Figure 7. 


\section{D Printing Adoption}

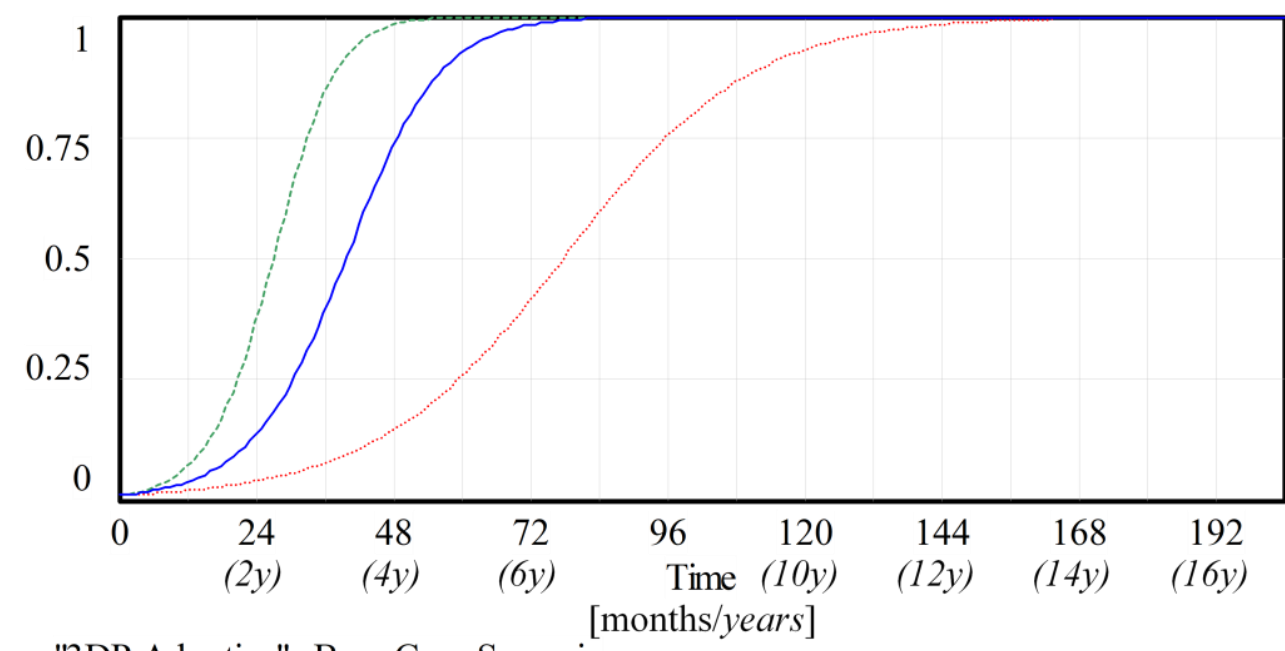

"3DP Adoption" : Base Case Scenario

[months/years]

"3DP Adoption" : 3DP Slower

"3DP Adoption" : 3DP Faster

Figure 7 - 3D printing adoption for different adoption speeds

The different speeds of 3DP adoption will have an impact on the availability of Fairphone accessories, as can be seen in Figure 8. In the scenario 3DP Slower, the required number of accessories for small network operators adopting the Fairphone (255, dashed horizontal line in Figure 8) will be achieved 2 years later than in the base case scenario.

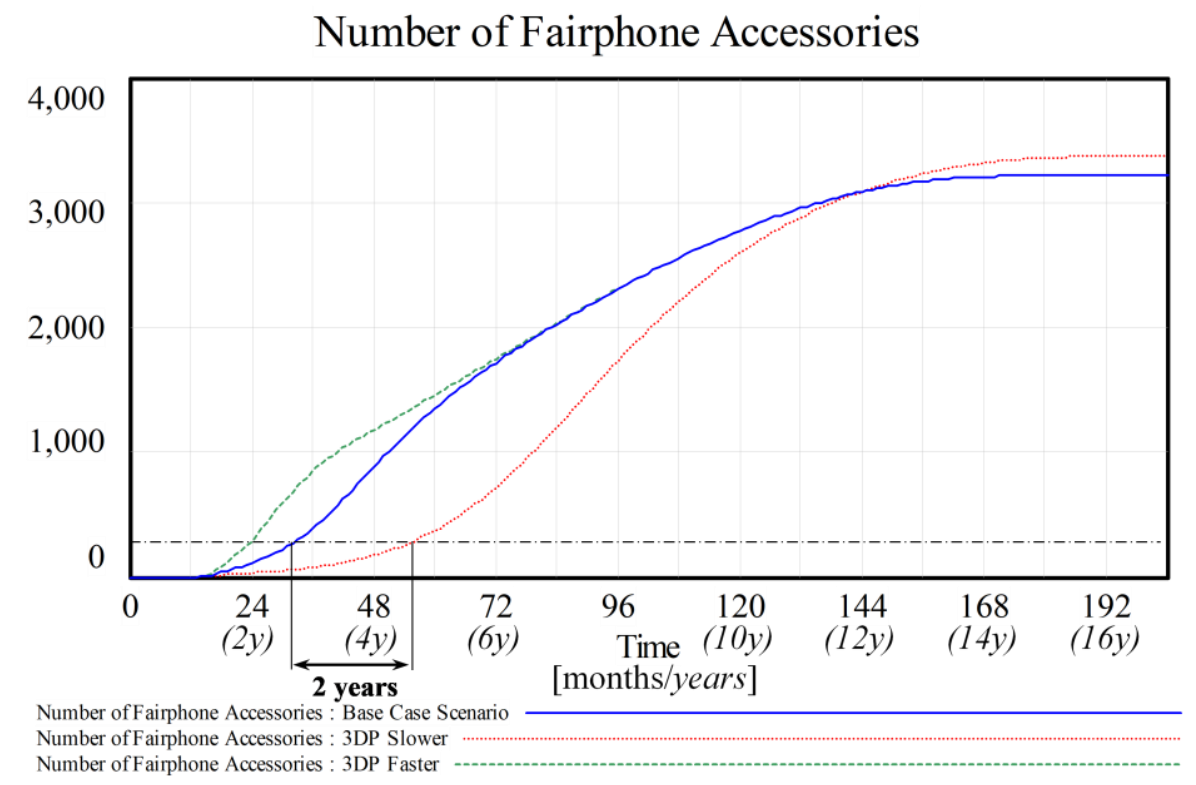


Figure 8 - Number of accessories available with different 3D printing adoption speeds

In Figure 9 we show the impact of the different 3DP Adoption Speeds (and resulting availability of accessories) on the total number of Fairphone customers. We see that the faster 3D printing adoption has no effect on the increase in number of customers (the green dashed line for '3DP Faster' coincides with the blue solid line of the 'Base Case Scenario'). However, a decrease in the $3 D$ Printing Adoption Speed has a much stronger effect because the adoption of the Fairphone by small network operators occurs much later. The adoption by large operators (555,000 cumulative sales, dashed horizontal line in Figure 9) occurs 15 months later than in the base case scenario. Such a delay can have devastating consequences on a start-up like Fairphone with limited resources and liquidity.

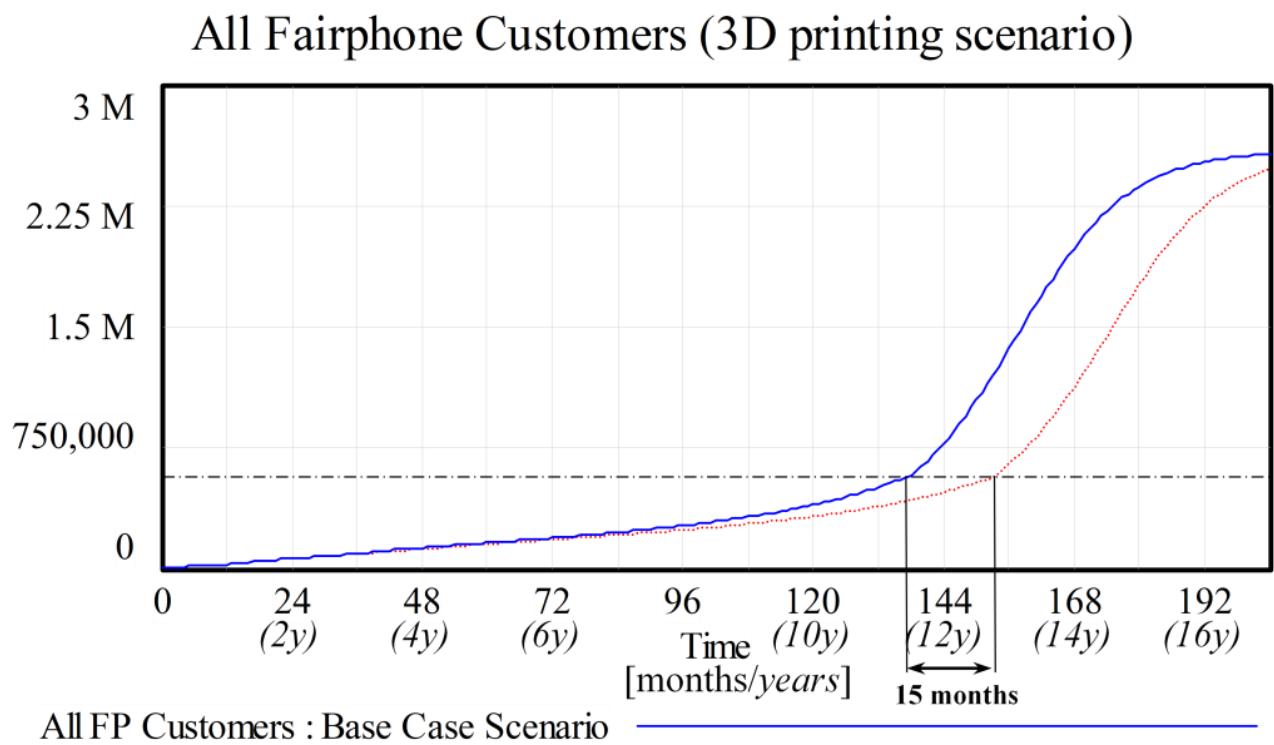

All FP Customers : Base Case Scenario

All FP Customers : 3DP Slower

All FP Customers : 3DP Faster 
Figure 9 - Total number of customers for different 3D printing adoption speeds ${ }^{11}$

\subsubsection{Impact of Societal Climate towards Sustainability}

The Societal Climate towards Sustainability is a parameter that multiplies the growth rate of Regular Customers. The higher this parameter, the faster the number of Regular Customers will increase. This parameter also determines the Adoption of Sustainability by Competitors. The higher this parameter, the more competitors will adopt sustainability practices in their supply chains. In addition to the base case scenario, we run a scenario Sustainable High (50\% higher) and a scenario Sustainable Low (50\% lower). The resulting evolution of the total number of Fairphone customers is shown in Figure 10.

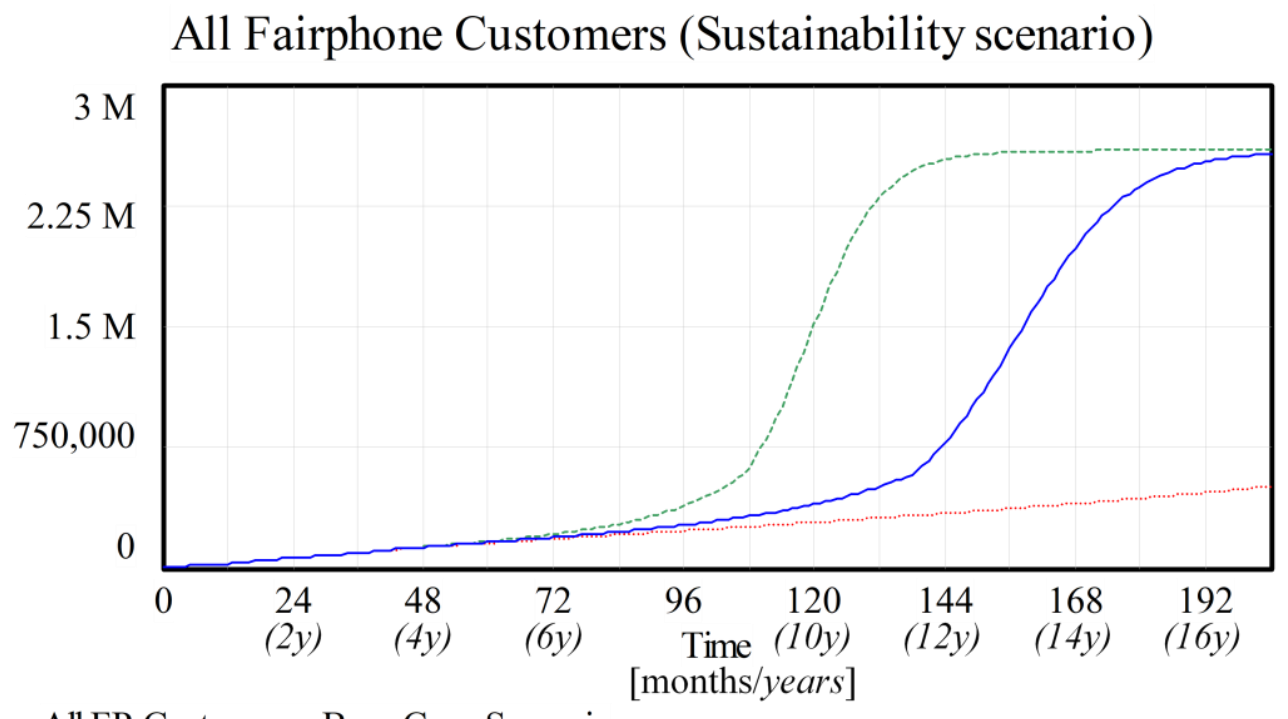

All FP Customers : Base Case Scenario

All FP Customers : Sustainable Low

All FP Customers : Sustainable High

Figure 10 - Evolution of customers with different levels of societal climate towards sustainability

\footnotetext{
${ }^{11}$ The green dashed line '3DP Faster' is not visible in this figure because it coincides with the blue solid line of 'Base Case Scenario'

(C) 2019. This manuscript version is made available under the CC-BY-NC-ND 4.0 license (http://creativecommons.org/licenses/by-nc-nd/4.0/)
} 
In Figure 10 we can see that customer growth is not affected by the different levels of Societal Climate towards Sustainability during the first 70 months (5.8 years). This is due to the fact that the initial customers of Fairphone (Fairness Customers and Openness Customers) have an intrinsic motivation to buy this product. Fairness Customers are already convinced about the importance of socially responsible supply chains and buy Fairphone for that reason. Openness Customers buy the Fairphone because they appreciate the firm's openness philosophy of sharing design files and encouraging users to design and 3D print their own accessories (until Month 55, 4.5 years). However, once Regular Customers start buying Fairphone through network operators, the Societal Climate towards Sustainability has a substantial impact on the number of customers. We see that the $50 \%$ increase in this parameter has a much smaller impact on the number of customers than the $50 \%$ decrease.

\subsection{Discussion}

This research set out to investigate how social sustainability could become a more pressing concern in a supply chain. It started with the premise that large firms may not have an imperative to focus on sustainability due to insufficient pressure from consumers (related amongst other factors to the distance between consumers and producers), while smaller firms may lack the resources to change the status quo (Pagell and Shevchenko, 2014; Shevchenko et al., 2016). The research focused on whether and how these issues could be alleviated by a small firm using 3DP technologies. While 3DP adoption has often been considered in terms of adoption by producers for the purpose of mass customisation (Weller et al., 2015; Hartl and Kort, 2017), we focused on the relationship between (consumer) 3DP and open design (e.g. Chan et al., 2018). We developed a systems dynamics model focusing on consumers' 3DP adoption and willingness to volunteer their effort in open design. The focus is not on additive manufacturing of complete products - in this case mobile phones - since this is not yet feasible in large volumes. Instead we examine how allowing consumers to design, share 
or 3D print accessories - phone cases - allows aftermarket customisation and may result in wider impacts. The impacts of the SCI we investigated can be compared to the disruptive innovation model of technological innovation, whereby new technologies redefine standards by satisfying previously unmet market needs (Christensen, 1997). In this case, we argue that there is an unmet and currently unrecognised need for social sustainability and that companies such as Fairphone can disrupt by addressing it. 3DP has been described as disruptive for some time (e.g. Beltagui et al., forthcoming), and this study contributes to an understanding of how it may achieve disruption. The study also confirms Abdelkafi and Pero's (2018) argument that SCI can drive business model innovation. For Fairphone, using 3DP instead of injection moulding (Minetola and Eyers, 2018) was the SCI that led to the business model innovation of involving customers in the open design of phone accessories.

\subsection{Theoretical Contributions}

The first notable finding of this research is empirical evidence for the assertion that small, innovative firms can introduce sustainability into established supply chains. We used empirical data on Fairphone's performance to date, as input and validation for the system dynamics model. Fairphone's growth has enabled distribution in mainstream markets through mobile phone networks. This places Fairphone in direct competition with more established, market leading, phone brands, raising the possibility that Fairphone's unique selling point its commitment to socially sustainable practices - will be imitated (Carter et al., 2017). Social sustainability is often implemented only in response to legal obligations such as the need to declare and avoid conflict minerals or slavery (Gold et al., 2015; Hofmann et al., 2018). Fairphone's access to mainstream markets would, however, make the commercial incentive clearer (Shevchenko et al., 2016). If larger firms apply their superior resources to improving 
sustainability in the mobile phone supply chain, Fairphone would achieve its mission of fairness, but may struggle to remain relevant. Hence in our model, the number of Fairness Customers reduces as the product becomes mainstream. These findings can be summarised in the form of the following research proposition:

P1: Small but innovative firms can stimulate adoption of sustainable SCI, but may struggle to compete once larger firms are persuaded to imitate the innovative practices.

The second, related finding, concerns the likelihood that consumers, concerned with social sustainability, may help improve the lives of workers in the supply chain. Early adopters (Fairness Customers here) play an important role in the S-curve of innovation adoption, helping to fund development before mainstream demand increases (Rogers, 2003). This effect has been seen in the adoption of sustainable product and supply chain innovations, including electric vehicles (Plötz et al., 2014), alternative fuel vehicles (Tran et al., 2013), sustainable energy solutions (Nygrén et al., 2015), and, most pertinent to the present study, fair-trade products (Levi and Linton, 2003; Low and Davenport, 2006). Early adopters are likely to be a niche market, often not large enough to make sustainability an order qualifier. The scenarios varying the parameter of Societal Climate towards Sustainability model the size of this niche and demonstrate the importance of sustainability values shared across society for diffusing sustainable SCI throughout an industry. For example, if awareness and interest in sustainability increase, our model suggests Fairphone may achieve its sustainability objectives much faster, whereas a 50\% reduction may see the market for sustainably produced phones remain niche. While researchers and journalists deplore instances of exploitative labour practices in supply chains (Chan and Pun, 2010; Huq et al., 2016; Kara, 2018; Sadof et al., 2018) this may not filter down into purchasing decisions if customers do not build up forceful pressure. This may in turn prevent firms pursuing social 
sustainability from influencing the status quo and prevent supply chains from achieving true sustainability (Pagell and Shevchenko, 2014).

An important role is played by those contributing through open design (Openness Customers in this model). Beyond early adopters, wider appeal for the innovation is increased by greater variety of accessories such as protective cases, but the limited design and production resources of a small firm limit the ability to offer such variety. These findings lead to the following research proposition:

P2: The societal climate towards sustainability can accelerate the adoption of sustainable SCI by increasing the likelihood of appealing to a mainstream market.

Our third important finding concerns the impact of openness. Firstly, our findings confirm the benefits of harnessing open design, in this case by opening the design and production of complementary products to customers. While small firms such as Fairphone may be innovative and use sustainability to appeal to a niche market (Caniato et al., 2012), their lack of resources restrict their ability to have a meaningful impact on the mainstream (Shevchenko et al., 2016). Our findings suggest that empowering customers through 3DP and open design can help overcome these restrictions. A greater variety in complementary products, designed by customers for distributed production by 3DP can accelerate market penetration. When the first small network operator adopted Fairphone, customers could choose from a variety of 255 accessories.

We selected the case of Fairphone in order to examine the impact of 3DP on SCI, because of the customer designed 3D printed accessories they made available. Open design is central to Fairphone's mission, given the founder's insistence that one cannot own a product that one cannot "open" (van Abel et al., 2011; TEDx, 2013). Even after ending its active promotion of 3DP accessories on its website, Fairphone maintained its openness philosophy, by sharing 
design files of its new phone on an open source file repository, communicating transparently about its cost structure and unveiling the names of its supply chain partners. While this openness attracts some individuals, it also restricts commercial exploitation of designs, encouraging many firms to use customers' inputs but restrict access to them. Open design communities typically resent a move from open to closed. For example, MakerBot Industries, created an open-designed 3D printer that became the market leader, but angered its users, customers and employees by then closing the designs to avoid imitation (West and Kuk, 2016). Similarly, in October 2018, 3D Hubs transformed its peer-to-peer 3DP network into a manufacturing platform open only to commercial 3DP businesses, ${ }^{12}$ which led to much resistance and criticism from users. A parallel to 3DP comes in the history of personal computers, where philosophical divisions between Apple's co-founders saw friction over how open (i.e. user customisable) products should be (Wozniak and Smith, 2006). While Apple has maintained a resistance to openness, the first signs have emerged that this could negatively impact performance - sales of phones have slowed as service revenues grow, suggesting that customers want to repair phones.

Finally, our findings contribute to the ongoing debates about whether and how 3DP is likely to have a revolutionary impact on business and society (e.g. D’Aveni, 2015; Bogers et al., 2016; Steenhuis and Pretorius, 2016). Several studies have investigated barriers to adoption of $3 \mathrm{DP}$, such as the costs of materials, the relatively slow speed of production as well as the technical quality of equipment and output (Chan et al., 2014; Chekurov et al., 2018). Such studies focus on adoption of 3DP in place of traditional manufacturing equipment, either for spare parts or original equipment. Weller et al. (2015) examine the impact of 3DP adoption on product pricing in a given industry. For example, they propose that a monopolist may

\footnotetext{
${ }^{12}$ https://www.3dhubs.com/blog/3d-hubs-announces-suite-of-new-features-and-switch-to-fulfilled-by-3d-hubs-2/

(C) 2019. This manuscript version is made available under the CC-BY-NC-ND 4.0 license (http://creativecommons.org/licenses/by-nc-nd/4.0/)
} 
increase profits with premium pricing for customised products, whereas entry of competitors using 3DP can lead to lower prices overall. This implies the use of 3DP for additive manufacturing, by companies, to create products for their customers. Our study focuses on complementary products - accessories such as mobile phone cases - which have a parallel supply chain as well as having different technical requirements. For example, 3DP technologies are much better suited to producing simple phone cases than complex products such as mobile phones. Moreover, our study examines the effect that consumer 3DP can have on market entry. Inflated expectations that every home may soon contain a 3D printer have captured the imagination of the public and placed 3DP on the political agenda, despite being considered unrealistic (Weller et al., 2015). Our simulation suggests that whether or not every home contains a 3D printer is not critical. Instead access rather than ownership is of concern. If there are a sufficient number of accessible devices, then the advantages are gained and can be reaped. Indeed, the ability to share resources and hence avoid capital investments, makes 3DP an important enabler of innovation and entrepreneurship, especially for small firms (De Jong and De Bruijn, 2013). These findings may be condensed into the following research proposition:

P3: The adoption of 3DP in society can increase the potential for firms to leverage open design because of broader access to production tools.

\subsection{Managerial Implications}

Our findings can help to inform managerial decisions with respect to pursuing socially sustainable SCI as well as on how to benefit from 3DP.

Regarding sustainability, a question remains over whether and why to embrace it. In the absence of legislation or sufficient consumer pressure, the incentives to do so are very limited. On the other hand, the threat of innovators adopting sustainable business and supply 
chain models and gaining market share through new production technologies and favourable societal climate, can be countered through imitation. For example, incumbents can seek to appeal to customers who value social sustainability through supply chain transparency and investments to improve working conditions along the supply chain. The reductions this may cause in short term profit margins can be offset by the reputational benefits and the appeal to customers who value sustainable principles. Our results suggest that an understanding of the societal climate towards sustainability is important, in order to gauge how successful sustainability-oriented competitors may be. While the larger size of incumbents is vital due to the bargaining power it brings when dealing with suppliers, small firms like Fairphone can overcome their size-related resource deficit and make a difference to supply chains. The future success of their model is measured not only by the market share for their products but by the extent to which the mobile phone supply chain as a whole becomes more sustainable. A notable feature of the system dynamics model is that it allows a longitudinal perspective to be taken, which enables us to see how different groups of consumers are targeted over time. In the initial stages, Fairphone appeals mostly to market niches, but for it to achieve its goals, growth into the mainstream is necessary. Innovation diffusion theories suggest that early and late adopters have differing characteristics, and innovators should focus on different groups over time (e.g. Rogers, 2003). This study suggests that focusing on customers concerned with sustainability and openess can help in establishing an innovation and providing a platform for mainstream market penetration. It also highlights that customers with the ability and willingness to contribute through open design represent a separate group, which can be engaged alongside the early adopters, again on the route to mainstream adoption. Managers must decide how and when to engage these groups because their interest in the innovation may wane as it becomes mainstream. 
3DP is considered to be a key element of industry 4.0 and its value is widely seen to lie in mass customisation, with small batches - as low as one - becoming economically feasible (Mellor et al., 2014; Chan et al., 2018). A key part of this is that "enterprises can co-design products with customers" (Dalenogare et al., 2018, p.385). It has been argued that 3DP may cause a paradigm shift comparable to the interned (Holmström and Partanen, 2014; Chekurov et al., 2018). Indeed, this paradigm shift comes in the way that the internet (along with the personal computer) has helped democratise innovation (von Hippel, 2005), by reducing the resource requirements for creating software in an open and collaborative manner (von Hippel and von Krogh, 2003; Wozniak and Smith, 2006). One of the greatest barriers to 3DP adoption in industry remains the concern over intellectual property rights, but this study demonstrates that sidestepping such concerns - through openness, can have important benefits. As future technologies evolve in a manner that combines digital and physical elements, we could expect that enabling openness can have a similar effect of supporting firms to overcome resource constraints, if they are willing to pursue the private-collective model, rather than maintaining control over all intellectual property (Lakhani and von Hippel, 2003; West and Kuk, 2016).

Weller et al. (2015, p.53) propose that "with higher penetration of [additive manufacturing] technology, competition will increase as AM technology enables manufacturers to offer a broad product range, resulting in inter-segment competition." Our results give some support to this proposition, since our model demonstrates that Fairphone offers a broader range of (complementary) products. However, a key addition is the important role that open design makes. Similarly, Weller et al. (2015) propose that, if the use of 3DP is widespread in an industry, incumbents should dominate new entrants due to economies of scale in production and scope in marketing or procurement. Fairphone helps us to contest these propositions by demonstrating the potential for a new entrant to win market share from incumbents. 
Fairphone is unlikely to dominate the mobile phone market, but by leveraging open design effort, which is made possible by the availability of 3DP, it is able to overcome the resource constraints that limit its production scale and marketing scope.

In this case, Fairphone began by encouraging users to design mobile phone cases and expanded this to include other accessories that can be 3D printed. The core product is manufactured using traditional methods but given the level of investment required in technology and manufacturing, developing a wide range of complementary products is not feasible for such a small firm. Therefore, using customer involvement is a valuable approach to consider. The appeal is partly that customers volunteer their effort, often due to intrinsic motivation and do not expect remuneration. The implications of reversing the openness later, however, can have very negative repercussions on customer loyalty and should therefore be carefully considered by managers. Sufficient mainstream customers, who are less inclined to devote effort and hence are less concerned with openness, should be targeted to compensate for the loss of interest from openness customers.

\subsection{Limitations and Further Research}

Yet, our approach of modelling the case of Fairphone based on empirical data with the aim of analysing different scenarios does not go without limitations. In line with general limitations of case study research, the findings of our research design cannot claim statistical generalisability but only a certain degree of theoretical generalisability (Yin, 2013). The latter is achieved by repeated reflection of model development and results with theory, and by transcending context-specific peculiarities through theory-led abstraction. Furthermore, the model is based on extensive longitudinal secondary data, but could be further validated by primary data collection, for instance through retrospective interviews with directors and 
managers of Fairphone. In fact, the system dynamics model of Fairphone may serve as a basis and starting point for follow-up research. It may be adapted to instances of sustainable SCI in other sectors as well as other applications of 3DP in supply chains, thus corroborating, refuting or refining the insights gained from this study. Finally, this study adds to the literature on 3DP by examining the indirect effects, i.e. focusing on the design and localised production of complementary products. As the adoption of 3DP and its application to mass customisation of a wider range of products increases, further research can examine empirical cases of open design as they emerge.

\subsection{References}

Abdelkafi, N. and Täuscher, K. (2015) "Business Models for Sustainability From a System Dynamics Perspective.” Organization \& Environment, Vol. 29, No. 1, pp.74-96.

Abdelkafi, N. and Pero, M. (2018) "Supply chain innovation-driven business models: Exploratory analysis and implications for management." Business Process Management Journal, Vol.24, No.2, pp.589-608.

Anderson, C. (2012) Makers: The New Industrial Revolution, New York, NY: Random House.

Arlbjørn, J.S., de Haas, H. and Munksgaard, K.B. (2011) "Exploring supply chain innovation.” Logistics Research, Vol. 3, No. 1, pp.3-18.

Autry, C.W. and Griffis, S.E. (2008) "Supply chain capital: the impact of structural and relational linkages on firm execution and innovation." Journal of Business Logistics, Vol. 29, No. 1, pp.157-173.

Bandyopadhyay, A., Gualtieri, T.P. and Bose, S. (2015) "Global Engineering and Additive Manufacturing." In: Bose S. (Ed.), Additive Manufacturing, pp.1-18, Boca Raton, FL: CRC Press.

Barnatt, C. (2013) 3D Printing: The Next Industrial Revolution, CreateSpace.

Beltagui, A., Rosli, A. and Candi, M (forthcoming) "Exaptation in a digital innovation ecosystem: the disruptive impacts of 3D printing.", Accepted for publication in Research Policy.

Bogers, M., Hadar, R. and Bilberg, A. (2016) "Additive manufacturing for consumer-centric business models: Implications for supply chains in consumer goods manufacturing." Technological Forecasting and Social Change, Vol. 102, pp.225-239. 
Candi, M. and Beltagui, A. (2019) "Effective use of 3D printing in the innovation process." Technovation, Vol. 80-81, pp.63-73.

Caviggioli, F. and Ughetto, E. (2019) "A bibliometric analysis of the research dealing with the impact of Additive Manufacturing on industry, business and society." International Journal of Production Economics, Vol. 208, pp.254-268.

Chan, H.K., Griffin, J., Lim, J.J., Zeng, F. and Chiu, A.S. (2018) "The impact of 3D Printing Technology on the supply chain: Manufacturing and legal perspectives." International Journal of Production Economics, Vol. 205, pp.156-162.

Christensen, C.M. (1997) Innovator's Dilemma: When new technologies cause great firms to fail, Boston, MA: Harvard Business School Press.

Caniato, F., Caridi, M., Crippa, L. and Moretto, A. (2012) "Environmental sustainability in fashion supply chains: An exploratory case-based research." International Journal of Production Economics, Vol. 135, No. 2, pp.659-670.

Carter, C.R., Kosmol, T., Kaufmann, L. (2017) "Toward a supply chain practice view." Journal of Supply Chain Management, Vol. 53, No. 1, pp.114-122.

Chekurov, S., Metsä-Kortelainen, S., Salmi, M., Roda, I. and Jussila, A. (2018) “The perceived value of additively manufactured digital spare parts in industry: An empirical investigation." International Journal of Production Economics, Vol. 205, pp.87-97.

Chan, J. and Pun, N. (2010) "Suicide as Protest for the New Generation of Chinese Migrant Workers : Foxconn, Global Capital, and the State." Asia-Pacific Journal: Japan Focus, Vol. 8, No. 2, pp.1-33.

Chen, J.Y. and Slotnick, S.A. (2015) "Supply chain disclosure and ethical sourcing." International Journal of Production Economics, Vol. 161, pp.17-30.

Chowdhury, R. (2017) "Rana Plaza Fieldwork and Academic Anxiety: Some Reflections." Journal of Management Studies, Vol. 54, No. 7, pp.1111-1117.

Crane, A. and Matten, D. (2016) Business ethics: Managing corporate citizenship and sustainability in the age of globalization. Oxford University Press.

D’Aveni, R.A. (2015) “The 3-D Printing Revolution.” Harvard Business Review, Vol. 93, No. 3, pp.41-48.

Dalenogare, L.S., Benitez, G.B., Ayala, N.F. and Frank, A.G. (2018) "The expected contribution of Industry 4.0 technologies for industrial performance." International Journal of Production Economics, Vol. 204, pp.383-394.

Davies, I.A. (2007) "The eras and participants of fair trade: an industry structure/stakeholder perspective on the growth of the fair trade industry." Corporate Governance: The International Journal of Business in Society, Vol. 7, No. 4, pp.455-470.

De Jong, J.P.J. and De Bruijn, E. (2013) "Innovation Lessons From 3-D Printing." MIT Sloan Management Review, Vol. 54, No. 2, pp.43-52. 
Despeisse, M., Baumers, M., Brown, P., Charnley, F., Ford, S.J., Garmulewicz, A., Knowles, S., Minshall, T.H.W., Mortara, L., Reed-Tsochas, F.P. and Rowley, J. (2017) "Unlocking value for a circular economy through 3D printing: A research agenda." Technological Forecasting and Social Change, Vol. 115, pp.75-84.

Dougherty, D. (2012) “The maker movement.” Innovations, Vol. 7, No. 3, pp.11-14.

Dyllick, T. and Hockerts, K. (2002) "Beyond the business case for corporate sustainability." Business Strategy and the Environment, Vol. 11, No. 2, pp.130-141.

Eltantawy, R. (2016) "Towards sustainable supply management: requisite governance and resilience capabilities.” Journal of Strategic Marketing, Vol. 24, No. 2, pp.118-130.

Fairphone (2014) "Launching Fairphone 3D-printed cases with 3D Hubs." July 7, 2014, available at https://www.fairphone.com/2014/07/07/launching-fairphone-3d-printed-caseswith-3d-hubs/, last accessed $14^{\text {th }}$ March 2018.

Forrester, J.W. (1961) Industrial Dynamics, Cambridge, MA: MIT Press.

Fox, S. (2014) “Third Wave Do-It-Yourself (DIY): Potential for prosumption, innovation, and entrepreneurship by local populations in regions without industrial manufacturing infrastructure." Technology in Society, Vol. 39, November 2014, pp.18-30.

Ghobadian, A., Talavera, I., Bhattacharya, A., Kumar, V., Garza-Reyes, J.A. and O'Regan, N. (2018) "Examining legitimatisation of additive manufacturing in the interplay between innovation, lean manufacturing and sustainability." International Journal of Production Economics, article in press.

Gold, S., Kunz, N. and Reiner, G. (2017) "Sustainable Global Agrifood Supply Chains: Exploring the Barriers.” Journal of Industrial Ecology, Vol. 21, No. 2, pp.249-260.

Gold, S., Trautrims, A. and Trodd, Z. (2015) "Modern slavery challenges to supply chain management." Supply Chain Management: An International Journal, Vol. 20, No. 5, pp.485494.

GRI [Global Reporting Initiative] (2013) G4 Sustainability Reporting Guidelines: Reporting Principles and Standard Disclosures [online], available at: https://www. globalreporting.org/resourcelibrary/GRIG4-Part1-Reporting-Principles-andStandard-Disclosures.pdf, last accessed 2 October 2018.

Halbinger, M.A. (2018) "The role of makerspaces in supporting consumer innovation and diffusion: An empirical analysis", Research Policy, Vol. 47, No. 10, pp.2028-2036.

Hartl, R.F. and Kort, P.M. (2017) "Possible market entry of a firm with an additive manufacturing technology." International Journal of Production Economics, Vol. 194, pp.190-199.

Hassini, E., Surti, C. and Searcy, C. (2012) "A literature review and a case study of sustainable supply chains with a focus on metrics." International Journal of Production Economics, Vol. 140, No. 1, pp.69-82.

Ho, J.C. and Lee, C.S. (2015) "A typology of technological change: Technological paradigm theory with validation and generalization from case studies." Technological Forecasting and Social Change, Vol. 97, pp.128-139. 
Hockerts, K. and Wüstenhagen, R. (2010) "Greening Goliaths versus emerging DavidsTheorizing about the role of incumbents and new entrants in sustainable entrepreneurship." Journal of Business Venturing, 25(5), pp.481-492.

Hoejmose, S.U., Grosvold, J. and Millington, A. (2013) "Socially responsible supply chains: power asymmetries and joint dependence." Supply Chain Management: An International Journal, Vol. 18, No. 3, pp.277-291.

Hofmann, H., Schleper, M.C. and Blome, C. (2018) "Conflict Minerals and Supply Chain Due Diligence: An Exploratory Study of Multi-tier Supply Chains.” Journal of Business Ethics, Vol. 147, No. 1, pp.115-141.

Huang, S.H., Liu, P., Mokasdar, A. and Hou, L. (2013) "Additive manufacturing and its societal impact: A literature review." International Journal of Advanced Manufacturing Technology, Vol. 67, No. 5-8, pp.1191-1203.

Huq, F.A., Chowdhury, I.N. and Klassen, R.D. (2016) "Social management capabilities of multinational buying firms and their emerging market suppliers: An exploratory study of the clothing industry." Journal of Operations Management, Vol. 46, pp.19-37.

Isaksson, R., Johansson, P. and Fischer, K. (2010) "Detecting Supply Chain Innovation Potential for Sustainable Development." Journal of Business Ethics, Vol. 97, No. 3, pp.425442.

Jahangirian, M., Eldabi, T., Naseer, A., Stergioulas, L.K. and Young, T. (2010) "Simulation in manufacturing and business: A review." European Journal of Operational Research, Vol. 203, No. 1, pp.1-13.

Jie, Y.U., Subramanian, N., Ning, K. and Edwards, D. (2015) "Product delivery service provider selection and customer satisfaction in the era of internet of things: A Chinese eretailers' perspective." International Journal of Production Economics, Vol. 159, pp.104116.

Jones, P., Comfort, D. and Hillier, D. (2003) "Retailing fair trade food products in the UK", British Food Journal, Vol. 105, No. 11, pp.800-810.

Khajavi, S.H., Partanen, J. and Holmström, J. (2014) "Additive manufacturing in the spare parts supply chain.” Computers in Industry, Vol. 65, No. 1, pp.50-63.

Kara, S. (2018) "Is your phone tainted by the misery of the 35,000 children in Congo's mines?" The Guardian US, 10/12/2018.

Karjalainen, K. and Moxham, C. (2013) "Focus on Fairtrade: Propositions for Integrating Fairtrade and Supply Chain Management Research." Journal of Business Ethics, Vol. 116, No. 2, pp.267-282.

Knofius, N., van der Heijden, M.C. and Zijm, W.H. (2019) “Consolidating spare parts for asset maintenance with additive manufacturing." International Journal of Production Economics, Vol. 208, pp.269-280.

Krabbe, M. (2007) “Leverage supply chain innovation.” Industrial Engineer, Vol. 39, No. 12, pp.26-30. 
Kunz, N., Reiner, G. and Gold, S. (2014) "Investing in disaster management capabilities versus pre-positioning inventory: A new approach to disaster preparedness." International Journal of Production Economics, Vol. 157, pp.261-272.

Kwak, D.-W., Seo, Y.-J. and Mason, R. (2018) "Investigating the relationship between supply chain innovation, risk management capabilities and competitive advantage in global supply chains." International Journal of Operations and Production Management, Vol. 38, No. 1, pp.2-21.

Lakhani, K.R., and Von Hippel, E. (2003) "How open source software works: "free" user-touser assistance.” Research Policy, Vol. 32, No. 6, pp.923-943.

Levi, M. and Linton, A. (2003) "Fair trade: A cup at a time?" Politics \& Society, Vol. 31, No. 3, pp.407-432.

Li, Y., Jia, G., Cheng, Y. and Hu, Y. (2017) “Additive manufacturing technology in spare parts supply chain: a comparative study." International Journal of Production Research, Vol. 55, No. 5, pp.1498-1515.

Lin, K.Y. and Lu, H.P. (2011) "Why people use social networking sites: An empirical study integrating network externalities and motivation theory." Computers in Human Behavior, Vol. 27, No. 3, pp.1152-1161.

Low, W. and Davenport, E. (2006) "Mainstreaming fair trade: adoption, assimilation, appropriation.” Journal of Strategic Marketing, Vol. 14, No. 4, pp.315-327.

Lucas, H.C. and Goh, J.M. (2009) "Disruptive technology: How Kodak missed the digital photography revolution." The Journal of Strategic Information Systems, Vol. 18, No. 1, pp.46-55.

Maloni, M.J. and Brown, M.E. (2006) "Corporate social responsibility in the supply chain: An application in the food industry." Journal of Business Ethics, Vol. 68, No. 1, pp.35-52.

Matthews, L., Power, D., Touboulic, A. and Marques, L. (2016) "Building bridges: Toward alternative theory of sustainable supply chain management." Journal of Supply Chain Management, Vol. 52, No. 1, pp.82-94.

Mellor, S., Hao, L. and Zhang, D. (2014) "Additive manufacturing: A framework for implementation.” International Journal of Production Economics, Vol. 149, pp.194-201.

Minetola, P. and Eyers, D. (2018) "Energy and cost assessment of 3D printed mobile case covers.” Procedia CIRP, Vol. 69, pp.130-135.

Mitchell, R.K., Agle, B.R. and Wood, D.J. (1997) "Toward a theory of stakeholder identification and salience: Defining the principle of who and what really counts." Academy of Management Review, Vol. 22, No. 4, pp.853-886.

Munksgaard, K.B., Stentoft, J. and Paulraj, A. (2014) "Value-based supply chain innovation." Operations Management Research, Vol. 7, No. 3-4, pp.50-62.

Nambisan, S. and Baron, R.A. (2009). "Virtual customer environments: testing a model of voluntary participation in value co-creation activities." Journal of Product Innovation Management, Vol. 26, No. 4, pp.388-406. 
Nygrén, N. A., Kontio, P., Lyytimäki, J., Varho, V. and Tapio, P. (2015) "Early adopters boosting the diffusion of sustainable small-scale energy solutions." Renewable and Sustainable Energy Reviews, Vol. 46, pp.79-87.

Pagell, M. and Shevchenko, A. (2014) "Why research in sustainable supply chain management should have no future." Journal of Supply Chain Management, Vol. 50, No. 1, pp.44-55.

Petrovic, V., Vicente Haro Gonzalez, J., Jorda Ferrando, O., Delgado Gordillo, J., Ramon Blasco Puchades, J. and Portoles Grinan, L. (2011) "Additive layered manufacturing: sectors of industrial application shown through case studies." International Journal of Production Research, Vol. 49, No. 4, pp.1061-1079.

Plötz, P., Schneider, U., Globisch, J. and Dütschke, E. (2014) "Who will buy electric vehicles? Identifying early adopters in Germany." Transportation Research Part A: Policy and Practice, Vol. 67, pp.96-109.

Porter, M.E. and Kramer, M.R. (2011) “Creating shared value." Harvard Business Review, Vol. 89, No. 1-2, pp.62-77

Raasch, C., Herstatt, C. and Balka, K. (2009) "On the open design of tangible goods." $R \& D$ Management, Vol. 39, No. 4, pp.382-393.

Reefke, H. and Sundaram, D. (2017) "Key themes and research opportunities in sustainable supply chain management - identification and evaluation.” Omega, Vol. 66, pp.195-211.

Reiner, G., Gold, S. and Hahn, R. (2015) "Wealth and health at the Base of the Pyramid: Modelling trade-offs and complementarities for fast moving dairy product case." International Journal of Production Economics, Vol. 170, pp.413-421.

Rogers, E. (2003) Diffusion of Innovations, New York, NY: Free Press.

Rogers, H., Baricz, N. and Pawar, K.S. (2016) "3D printing services: Classification, supply chain implications and research agenda." International Journal of Physical Distribution \& Logistics Management, Vol. 46, No. 10, pp.886-907.

Russo, M.V. and Fouts, P.A. (1997) "A resource-based perspective on corporate environmental performance and profitability." Academy of Management Journal, Vol. 40, No. 3, pp.534-559.

Sadof, K. D., Mucha, L. and Frankel, T. C. (2018) "The hidden costs of cobalt mining." The Washington Post, 02/28/2018.

Santos, S.P., Belton, V. and Howick, S. (2002) "Adding value to performance measurement by using system dynamics and multicriteria analysis." International Journal of Operations \& Production Management, Vol. 22, No. 11, pp.1246-1272.

Schniederjans, D.G. (2017) "Adoption of 3D-printing technologies in manufacturing: A survey analysis.” International Journal of Production Economics, Vol. 183, pp.287-298.

Shevchenko, A., Lévesque, M. and Pagell, M. (2016) "Why Firms Delay Reaching True Sustainability.” Journal of Management Studies, Vol. 53, No. 5, pp.911-935. 
Steenhuis, H.J. and Pretorius, L. (2016) "Consumer additive manufacturing or 3D printing adoption: an exploratory study." Journal of Manufacturing Technology Management, Vol. 27, No. 7, pp.990-1012.

Sterman, J.D. (2000) Business Dynamics: Systems Thinking and Modeling for a Complex World, New York, NY: Irwin/McGraw-Hill.

TEDx (2013) "Bas van Abel (Fairphone): Finding the right kind of screwdriver" available from https://tedx.amsterdam/2013/11/bas-van-abel-of-fair-phone-finding-the-right-kind-ofscrew-driver/, last accessed $14^{\text {th }}$ March, 2018.

Thomas-Seale, L.E.J., Kirkman-Brown, J.C., Attallah, M.M., Espino, D.M. and Shepherd, D.E.T. (2018) "The barriers to the progression of additive manufacture: Perspectives from UK industry." International Journal of Production Economics, Vol. 198, pp.104-118.

Tran, M., Banister, D., Bishop, J.D.K. and McCulloch, M.D. (2013) "Simulating early adoption of alternative fuel vehicles for sustainability." Technological Forecasting and Social Change, Vol. 80, No. 5, pp.865-875.

Van Abel, B., Evers, L., Klaasen, R. and Troxler, P. (Eds.) (2011) Open Design Now: Why Design Cannot Remain Exclusive, Amsterdam: BIS.

Von Hippel, E. and von Krogh, G. (2003) "Open source software and the "private-collective" innovation model: Issues for organization science." Organization Science, Vol. 14, No. 2 , pp.209-223.

Von Hippel, E. (2005) Democratizing innovation, Boston, MA: MIT Press.

Waller, M.A. and Fawcett, S.E. (2014) "Click here to print a maker movement supply chain: how innovation and entrepreneurship will disrupt supply chain design." Journal of Business Logistics, Vol. 35, No. 2, pp.99-102.

Walter-Herrmann, J. (2013) "FabLabs - a global social movement?" In: Walter-Hermann, J. and Büching, C. (Eds.) FabLab: Of Machines, Makers and Inventors, pp.33-45, Bielefeld: Transcript Verlag.

WCED (World Commission on Environment and Development) (1987) Our Common Future, Oxford, UK: Oxford University Press.

Weller, C., Kleer, R. and Piller, F.T. (2015) "Economic implications of 3D printing: Market structure models in light of additive manufacturing revisited." International Journal of Production Economics, Vol. 164, pp.43-56.

West, J. and Kuk, G. (2016) "The complementarity of openness: How MakerBot leveraged Thingiverse in 3D printing." Technological Forecasting and Social Change, Vol. 102, pp.169-181.

Wozniak, S. and Smith, G. (2006) iWoz: From Computer Geek to Cult Icon: How I Invented the Personal Computer, Co-founded Apple, and Had Fun Doing it, New York, NY: W. W. Norton \& Co. 
Yawar, S.A. and Seuring, S. (2017) "Management of social issues in supply chains: A literature review exploring social issues, actions and performance outcomes." Journal of Business Ethics, Vol. 141, No. 3, pp.621-643.

Yin, R.K. (2013) "Validity and generalization in future case study evaluations." Evaluation, Vol. 19, No. 3, pp.321-332.

Zhang, M., Zhao, X., Voss, C. and Zhu, G. (2016) "Innovating through services, co-creation and supplier integration: Cases from China." International Journal of Production Economics, Vol. 171, pp.289-300.

Zorzini, M., Hendry, L.C., Huq, F.A. and Stevenson, M. (2015) "Socially responsible sourcing: Reviewing the literature and its use of theory." International Journal of Operations \& Production Management, Vol. 35, No. 1, pp.60-109 


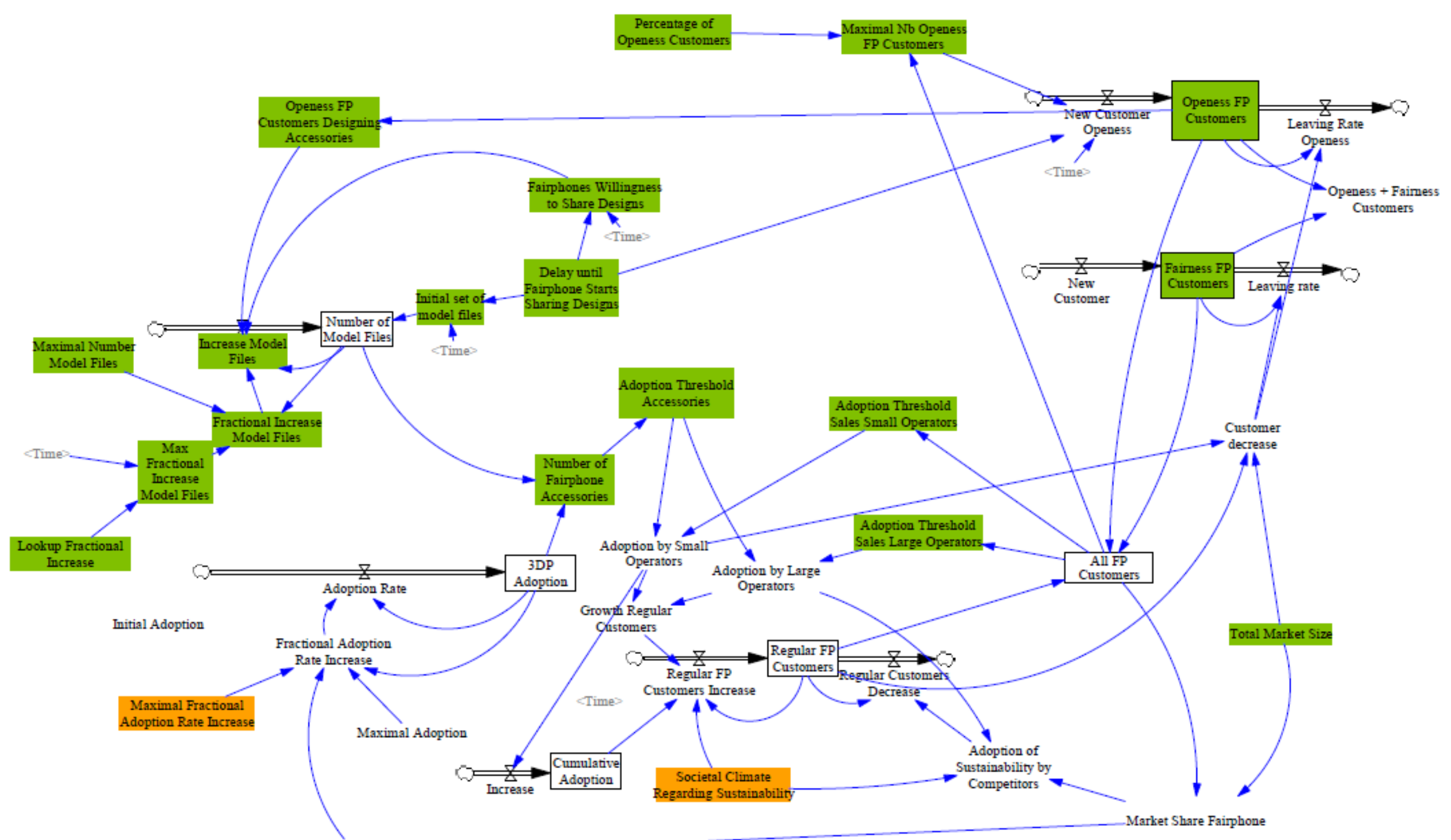

Reinforcing effect of 